\title{
Female Sex and Brain-Selective Estrogen Benefit $\alpha$-Synuclein Tetramerization and the PD-like Motor Syndrome in 3K Transgenic Mice
}

\author{
Molly M. Rajsombath, ${ }^{1} \oplus^{-A}$ Alice Y. Nam, ${ }^{1}{ }^{-}$Maria Ericsson, ${ }^{2}$ and Silke Nuber ${ }^{1}$ \\ ${ }^{1}$ Ann Romney Center for Neurologic Diseases, Brigham and Women's Hospital and Harvard Medical School, Boston, Massachusetts 02115, and 2Electron \\ Microscopy Laboratory, Department of Cell Biology, Harvard Medical School, Boston, Massachusetts 02115
}

Many studies report a higher risk for Parkinson's disease (PD) and younger age of onset in men. This, and the fact that the neuropathological process underlying PD symptoms may begin before menopause, suggests that estrogen-based hormone therapy could modify this higher risk in males. However, the effects of female sex or estrogen on $\alpha$-synuclein $(\alpha S)$ homeostasis and related PD neuropathology remain unknown. Here, we used an $\alpha$ S tetramer-abrogating mouse model of PD (3K) that amplifies the familial E46K PD mutation to investigate the effects of female sex and brain-selective estrogen treatment on $\alpha S$ tetramerization and solubility, formation of vesicle-rich $\alpha S^{+}$aggregates, dopaminergic and cortical fiber integrity, and associated motor deficits. In male $3 \mathrm{~K}$ mice, the motor phenotype became apparent at $\sim 10$ weeks and increased to age 6 months, paralleled by PD-like neuropathology, whereas $3 \mathrm{~K}$ females showed a significant delay in onset. At 6 months, this beneficial phenotypic effect in $3 \mathrm{~K}$ females was associated with a higher $\alpha \mathrm{S}$ tetramer-to-monomer ratio and less decrease in dopaminergic and cortical fiber length and quantity. Brain-selective estrogen treatment in symptomatic $3 \mathrm{~K}$ mice significantly increased the tetramer-to-monomer ratio, turnover by autophagy of aggregate-prone monomers, and neurite complexity of surviving DAergic and cortical neurons, in parallel with benefits in motor performance. Our findings support an upstream role for $\alpha \mathrm{S}$ tetramer loss in PD phenotypes and a role for estrogen in mitigating PD-like neuropathology in vivo. Brain-selective estrogen therapy may be useful in delaying or reducing PD symptoms in men and postmenopausal women.

Key words: $\alpha$-synuclein; DHED; estrogen; monomer; sex; tetramer

Significance Statement

The mechanisms responsible for the male-to-female preponderance in Parkinson's disease (PD) are not well understood yet important for treatment efficacy. We previously showed that abrogating native $\alpha$-synuclein $(\alpha S)$ tetramers produces a close PD model, including dopaminergic and cortical fiber loss and a progressive motor disorder responsive to L-DOPA. Here, we analyzed sex and use 10b-17 $\beta$-dihydroxyestra-1,4-dien-3-one treatment of symptomatic $3 \mathrm{~K}$ males, and demonstrate that the beneficial effects of female sex on PD-like neuropathology can be reinstated by elevating estrogen in the male brain. The study provides evidence that $17 \beta$-estradiol restores the tetramer-to-monomer ratio by autophagy turnover of excess $\alpha S$ monomers, vesicle and fiber integrity in brain regions critically involved in motor behavior. These data provide the basis for understanding sex differences in $\alpha \mathrm{S}$ homeostasis and the development of therapeutic approaches to treating men and postmenopausal women with PD.

\section{Introduction}

Parkinson's disease (PD) is an age-related neurodegenerative disorder characterized by accumulation of $\alpha$-synuclein $(\alpha S)$ in

\footnotetext{
Received Feb. 7, 2019; revised July 12, 2019; accepted July 23, 2019.

Author contributions: M.M.R., A.Y.N., M.E., and S.N. designed research; M.M.R., A.Y.N., M.E., and S.N. performed research; M.M.R., A.Y.N., M.E., and S.N. analyzed data; M.M.R., A.Y.N., and M.E. edited the paper; S.N. wrote the paper.

This work was supported by National Institutes of Health Grants NS103123 and NS109510 to S.N., the Orchard Foundation and the Women's Brain Initiative to S.N. We thank Ursula Kaiser, Ulf Dettmer, Dennis Selkoe, and laboratory members for helpful discussions; Viriatos Cardoso for help with mouse genotyping; and Barbara Caldarone for gait scan analyses and for helpful discussions in the behavioral experiments.
}

cytoplasmic inclusions termed Lewy bodies (LB) and neurites, progressive neuron loss, and motor deficits (Goedert, 2001). Abundant evidence suggests that the male sex is a risk factor for $\mathrm{PD}$ and may correlate with younger age of onset (Kurtzke and Goldberg, 1988; Baldereschi et al., 2000; Alves et al., 2008). In addition, factors reducing estrogen stimulation during life were

The authors declare no competing financial interests.

Correspondence should be addressed to Silke Nuber at snuber@bwh.harvard.edu.

https://doi.org/10.1523/JNEUROSCI.0313-19.2019

Copyright $\odot 2019$ the authors 
associated with the development of PD (Ragonese et al., 2004, 2006; Rocca et al., 2008). Furthermore, prospective and casecontrol studies have demonstrated that estrogen mitigates PD symptoms in women (Blanchet et al., 1999; Tsang et al., 2000). Most epidemiological studies evaluating exogenous estrogen use and risk of PD among women showed decreased risk (Dye et al., 2012; Bourque et al., 2019). However, efficacy of estrogen therapy in PD has been debated in light of detrimental peripheral side effects, such as stroke and breast cancer (Rossouw et al., 2002). Additionally, new studies examining the association between use of different estrogen formulations and PD risk demonstrated an unexpected higher risk of PD (Lundin et al., 2014). These studies highlight the need to better understand the role of estrogen in PD pathogenesis and to optimize the safety of therapeutic estrogen.

Some evidence suggests that estrogens and/or female sex may protect from PD-relevant environmental factors, such as paraquat (Gélinas et al., 2004), and other dopaminergic toxin-based models, such as MPTP and 6-OHDA (Gillies et al., 2014). These models showed that, on cellular level, estrogens have neurotrophic effects on midbrain dopaminergic (DAergic) neurons by promoting growth of neurites (Reisert et al., 1987), increasing tyrosine hydroxylase $(\mathrm{TH})$ expression in neonates (Ivanova and Beyer, 2003) and enhancing survival of DAergic neurons derived from human stem cells (Kishi et al., 2005). Although the neuroprotective action has been well established, the underlying mechanisms are not yet clear in these models since they do not address in vivo $\alpha \mathrm{S}$ protein aggregation.

To begin investigating the effect of estrogen on the $\alpha \mathrm{S}$-induced brain pathology, we used the tetramer-abrogating mouse model of $\mathrm{PD}$, " $3 \mathrm{~K}$," producing a phenotypic amplification of familial (fPD) E46K in living mice (Nuber et al., 2018). The $3 \mathrm{~K}$ transgenic mice exhibit many features of PD neuropathology. These include an upstream loss of aggregate-resistant tetramers (Bartels et al., 2011; Xu et al., 2018) with a consequent excess of $\alpha$ S monomers that vastly accumulate as vesicle-rich aggregates, preceding round LB-like inclusion pathology in aged $3 \mathrm{~K}$ brain, cortical and DAergic neurite loss, and display a robust early-onset and L-DOPA responsive motor phenotype (Nuber et al., 2018). To both control and specify for potential estrogen effects on the $\alpha S$-induced neuropathology, we used 10b-17 $\beta$-dihydroxyestra1,4-dien-3-one (DHED), which selectively increases estrogen in the brain while sparing the periphery from estrogenic stimulation (Prokai et al., 2015).

In this study, we compare $3 \mathrm{~K} \alpha \mathrm{S}$ sex differences and the effect of brain-selective estrogen-therapy in symptomatic 3K PD-like mice.

\section{Materials and Methods}

Treatment of $3 \mathrm{~K}$ mutant mice. For the study, we used $3 \mathrm{~K}$ mice (line \#3817) and expression-matched WT mice (line \#3877) with 2- to 3 -fold overexpression of human (hu) $\alpha \mathrm{S}$ controlled by the Thy1.2 promoter (generation and characterization described previously (Nuber et al., 2018). Briefly, all mice were bred to the C57BL/6J background, and the 3K-3817 colony was maintained by breeding female $3 \mathrm{~K}$ mice to nontransgenic (Ntg) C57BL/6J males due to severe motor phenotypes of $3 \mathrm{~K}$ males that interfered with breeding after 2 months of age (Nuber et al., 2018). Since dopamine (DA) neurotransmitter level may vary due to maternal care (Gammie et al., 2008), we chose Ntg littermates to analyze DA content, neuronal counts, and associated fiber densities and/or to test for earliest motor differences of newly weaned (4 week) mice. For treatment studies and for comparison of the motor behavior of mature mice ( 6 months and older), we used expression-matched WT control mice. All mice were bred and maintained at the Hale BTM facility in accordance with National Institutes of Health guidelines on use of laboratory animals and an approved protocol by the Brigham and Women's Hospital. Mice were kept in normal $12 \mathrm{~h} \mathrm{light} / 12 \mathrm{~h}$ dark cycles and had free access to food and water. For DHED treatment: mice received daily DHED (Sigma-Aldrich, SML 1642; $100 \mu \mathrm{g} / \mathrm{kg}$ in corn oil, s.c.) for up to $90 \mathrm{~d}$ and at least $2 \mathrm{~h}$ before the start of behavioral testing in a randomized, blinded design. All mice were sacrificed after a final behavioral assessment at 10 months of age.

Intact-cell crosslinking of brain tissue. Dissected cortical brain regions were gently minced into small bits with a razor blade, and the brain bits were washed free of released cytosol and resuspended in PBS with EDTAfree Complete protease inhibitors (Roche Diagnostics). Intact-cell crosslinking was then conducted on the washed brain bits as previously described (Nuber et al., 2018). Briefly, the cell-permeable crosslinker DSG was prepared at $1 \mathrm{~mm}$ final concentration in DMSO immediately before use. Samples were incubated with crosslinker for $30 \mathrm{~min}$ at $37^{\circ} \mathrm{C}$ with rotation. The reaction was quenched by adding Tris, $\mathrm{pH}$ 7.6, at 100 $\mathrm{mm}$ final concentration and incubated for $5 \mathrm{~min}$ at room temperature. After quenching and aspiration of the supernatant, proteins in intact tissue were extracted directly in TBS/1\% Triton X-100 (see below).

Sequential tissue extractions. Mice were anesthetized, decapitated, and the brains dissected on a chilled stage. Sequential extractions were performed as described previously (Nuber et al., 2013). Briefly, tissues were homogenized in 2.5 volumes of $\mathrm{TBS}^{+}(50 \mathrm{~mm}$ Tris- $\mathrm{HCl}, \mathrm{pH} 7.4,175 \mathrm{~mm}$ $\mathrm{NaCl}, 5 \mathrm{~mm}$ EDTA, protease inhibitor cocktail, Calbiochem) and spun for $30 \mathrm{~min}$ at $120,000 \times \mathrm{g}$. The pellet was subsequently extracted in $\mathrm{TBS}^{+}$ containing $1 \%$ Triton $\mathrm{X}-100$. The Triton X-100-insoluble pellet was then extracted in RIPA buffer $\left(\mathrm{TBS}^{+}, 1 \%\right.$ NP-40, $0.5 \%$ sodium deoxycholate, $0.1 \%$ SDS), with each extraction step followed by ultracentrifugation for $30 \mathrm{~min}$ at $120,000 \times \mathrm{g}$.

Western blot (WB) analyses. For WB, $8-15 \mu \mathrm{g}$ total protein of sequential extracts of dissected mouse brains was each run on $4 \%-12 \%$ Bis-Tris gels (Invitrogen) and electroblotted onto nitrocellulose membranes (Millipore). All cross-linked samples were blotted on PVDF membranes for enhanced retention of proteins. For improved immunodetection of $\alpha \mathrm{S}$ (monomers of which are prone to washing off filters) (Lee and Kamitani, 2011; Newman et al., 2013), the membranes were fixed in 4\% PFA for $10 \mathrm{~min}$. After washing in PBST (PBS with $0.2 \%$ Tween 20), membranes were blocked for $1 \mathrm{~h}$ at room temperature in PBS containing 5\% BSA. Blots were then incubated with hu-specific $\alpha$ S antibody (ab) (15G7, Enzo Life Sciences; 1:500), or antibodies that recognize both rodent and human $\alpha$ S (syn1, clone 42, BD Bioscience; 1:2000), LAMP-1 (25245, 1:1000; Abcam), LC3B (5F10; 1:2000; Nanotools) in PBST containing $5 \%$ BSA overnight. After washing with PBST, membranes were probed with appropriate secondary antibodies (1:3000, American Qualex), visualized with enhanced chemiluminescence (PerkinElmer), and analyzed with the VersaDoc gel imaging system. Proteins were normalized to $\beta$-actin (A5441, Sigma-Aldrich; 1:3000) used as a loading control. Quantification of signal intensities was performed as described previously (Nuber et al., 2008).

Estradiol measurement. 17 $\beta$-Estradiol levels of brainstem tissue extracts were measured using the high sensitive ELISA (ADI-900-174, Enzo Life Sciences) as previously described (Chen et al., 2013; Zhang et al., 2014; Lu et al., 2019) and in accordance to the manufacturer. Briefly, frozen brainstems were homogenized in $200 \mu \mathrm{l}$ of TBS buffer and protease inhibitor on ice using ultrasonication until complete dispersion of tissue into the buffer. Samples were centrifuged at 15,000 $\times g$ for $30 \mathrm{~min}$ at $4^{\circ} \mathrm{C}$, and the supernatants were collected. Each sample was then ether extracted by adding 5:1 (v/v) diethyl ether, and the organic phase was completely dried prior resuspension in $250 \mu \mathrm{l}$ of assay buffer. Subsequently, $100 \mu \mathrm{l}$ of sample was added in duplicates to the bottom of the appropriate wells followed by the addition of $50 \mu \mathrm{l} 17 \beta$-estradiol conjugated to alkaline phosphatase and $50 \mu$ l sheep polyclonal antibody to $17 \beta$-estradiol. Next, the plate was incubated at room temperature with shaking ( $\sim 500 \mathrm{rpm})$ for $2 \mathrm{~h}$. After 3 washes with $400 \mu \mathrm{l}$ of wash buffer, $200 \mu \mathrm{l}$ of the pNpp substrate solution was added into each well and incubated for $1 \mathrm{~h}$ at room temperature without shaking. Stop solution $(50 \mu \mathrm{l})$ was added afterward, and the optical density was read at $405 \mathrm{~nm}$. $17 \beta$-Estradiol levels in the protein samples were determined based on an established standard and expressed as $\mathrm{pg} / \mathrm{mg}$ wet brain weight. 
RNA. Total RNA samples were isolated from brain cortices using mirVana miRNA Isolation Kit (AM1561), and RNA concentrations determined by Nanodrop. The samples were converted into cDNA using Applied Biosystems High-capacity cDNA reverse transcription kit (\#4368813). Afterward, the cDNA was mixed with TaqMan Fast Universal PCR Mix (\#4352042) for qPCR analysis using TaqMan Gene Expression primers Esr1 (Mm00433149_m1), Calb (Mm00486647_m1), Tfeb (Mm00448968),Lamp-1 (Mm00495262_m1), Map1lc3a (Mm00458724_m1), and stearoyl-CoA desaturase-1 (SCD-1) (Mm00772290).

High pressure liquid chromatography (HPLC). HPLC was conducted as previously described (Nuber et al., 2013). To estimate striatal monoamine levels at age 6 months in $3 \mathrm{~K} \alpha \mathrm{S} \operatorname{tg}(n=5$ per group) or Ntg control mice ( $n=5$ or 6 per group). The mice were deeply anesthetized by $\mathrm{CO}_{2}$, quickly decapitated, and the striata dissected on ice, homogenized in 0.5 m perchloric acid, centrifuged, filtered, and stored at $-80^{\circ} \mathrm{C}$ until analysis for monoamine content. Samples containing 500 pg dihydroxybenzylamine as an internal standard were analyzed by HPLC with electrochemical detection. The column was an ET 125/2, Nucleosil 120-5, C-18 reversed-phase column (Macherey \& Nagel). The mobile phase consisted of $75 \mathrm{~mm} \mathrm{NaH}_{2} \mathrm{PO}_{4}, 4 \mathrm{~mm} \mathrm{KCl}, 20 \mu \mathrm{M}$ EDTA, $1.5 \mathrm{~mm}$ SDS, $100 \mu \mathrm{l} / \mathrm{l}$ diethylamine, $12 \%$ methanol, and $12 \%$ acetonitrile, adjusted to $\mathrm{pH} 6.0$ using phosphoric acid. The electrochemical detector (Intro, Antec) was set at $500 \mathrm{mV}$ vs. an ISAAC reference electrode (Antec) at $30^{\circ} \mathrm{C}$.

Immunohistochemistry. Anesthetized mice were intracardially perfused with PBS and ice-cold 4\% (w/v) PFA in PBS, pH 7.4. The brain was dissected from the skull and postfixed in $4 \%$ PFA for another $48 \mathrm{~h}(\mathrm{~h})$ at $4^{\circ} \mathrm{C}$. Brains were cut into $25 \mu \mathrm{m}$ cryotome sections and immunostained as described previously (Nuber et al., 2008). Briefly, after treatment with $\mathrm{H}_{2} \mathrm{O}_{2}(0.3 \%$ in PBS, $30 \mathrm{~min})$ and blocking ( $10 \%$ normal goat serum, $1 \mathrm{~h}$ ), sections were incubated for $12 \mathrm{~h}$ at $4^{\circ} \mathrm{C}$ with anti human $\alpha \mathrm{S}$ (15G7; 1:500, Enzo Life Sciences), anti phosphorylated (pSER129) $\alpha$ S (51253; 1:50,000; Abcam) in PBS. After washing with PBS, sections were incubated with the respective biotinylated secondary antibodies (1:200 in PBS; Vector Laboratories) and subsequently transferred into ABC solution (1:500 in PBS; Vectastain Elite Kit, Vector Laboratories) for $1 \mathrm{~h}$ and visualized with DAB. Fluorescence labeling was performed as described previously $(\mathrm{Nu}-$ ber et al., 2013). Briefly, sections were blocked in 10\% normal donkey serum and incubated overnight at $4^{\circ} \mathrm{C}$ with antibodies to hu $\alpha \mathrm{S}$ (15G7, 1:1000; Enzo Life Sciences), antiphosphorylated (pSER 129) $\alpha \mathrm{S}$ (51253, 1:4000; Abcam), LAMP-1 (25245, 1:500; Abcam), anti-LC3B (5F10, 1:500; Nanotools), ER $\alpha$ (MA5-13065, 1:2000; Invitrogen), or vesicular monoamine transporter 2 (VMAT2) (GTX89638, 1:2000; GeneTex). This was followed by incubation with FITC-conjugated secondary antibodies (1:500 in PBS) for $3 \mathrm{~h}$ at room temperature. Confocal microscopy was conducted with an Axiovert 35 microscope (Carl Zeiss) mounted on a MRC1024 laser scanning confocal microscope (Bio-Rad). For confocal images of $\mathrm{ER} \alpha$, LAMP-1, or LC3B with pSER 129-reactive- $\alpha$ S, each image was color-balanced. An ImageJ plug-in called "colocalization highlighter" created a mask of either LAMP-1 or LC3B pixels that overlapped with pSER129- $\alpha$ S pixels. The sizes of the colocalized pixels on the resultant 8-bit images were quantified using the analyze particle function plugin of ImageJ. For Golgi-Cox stainings, brains of $n=6$ mice per group were dissected from the skull and incubated in rapid Golgi-Cox solutions for $14 \mathrm{~d}$, following manufacturer's instructions (FD Rapid GolgiStain Kit, FD Neurotechnologies). For neuron reconstruction and analyses of the fiber length, the Golgi-impregnated cortical neurons and dendritic tree were examined in detail by LM imaging, and stacks of serial optical sections were captured with Carl Zeiss LM microscope equipped with a $40 \times$ oil-immersion objective. One researcher, blinded to genotype, selected, traced, and analyzed the apical and basal dendrites using Neuron Studio. Sections between bregma $\sim 1.9$ and $0.6 \mathrm{~mm}$ were used to select neurons to trace dendritic arbors in the motor cortex and somatosensory cortex. Regional boundaries were defined according to the mouse brain atlas (Franklin and Paxinos, 2008). 3D reconstructions of dendritic arborization generated using NeuronStudio software package (http:// research.mssm.edu/cnic/tools-ns.html) and the dendritic length were summed over the entire dendritic tree.

Electron microscopy. Briefly, mice underwent transcardiac perfusion with $4 \%$ paraformaldehyde (PFA), and the dissected brains were fixed in
4\% PFA for another $48 \mathrm{~h}$, followed by $2 \%$ PFA incubation for $24 \mathrm{~h}$, and then transferred into $0.5 \%$ PFA. For morphological TEM studies, $1 \times 1$ $\mathrm{mm}$ brain slices were postfixed overnight in $2.5 \%$ glutaraldehyde, $1.25 \%$ $\mathrm{PFA}$, and $0.03 \%$ picric acid in $0.1 \mathrm{M}$ sodium cacodylate buffer, $\mathrm{pH} 7.4$, washed $3 \times$ in $0.1 \mathrm{~m}$ sodium cacodylate buffer, incubated in $1 \%$ osmium tetroxide $(\mathrm{OsO} 4) / 1.5 \%$ potassium ferrocyanide $(\mathrm{KFeCN} 6)$ for $1 \mathrm{~h}$, washed in water $2 \times, 1 \times$ in $50 \mathrm{~mm}$ maleate buffer, $\mathrm{pH} 5.15(\mathrm{MB})$, and incubated in $1 \%$ uranyl acetate in $\mathrm{MB}$ for $1 \mathrm{~h}$ followed by 1 wash in $\mathrm{MB}$, 2 washes in water, and subsequent dehydration in grades of alcohol (10 min each; 70\%, 90\%, $2 \times 10 \mathrm{~min} 100 \%)$. The samples were then put in propyleneoxide for $1 \mathrm{~h}$ and infiltrated overnight in a 1:1 mixture of propyleneoxide and TAAB Epon (TAAB Laboratories Equipment; https://taab.co.uk). The following day, the samples were embedded in fresh TAAB Epon and polymerized at $60^{\circ} \mathrm{C}$ for $48 \mathrm{~h}$. Each block was cut into $60 \mathrm{~nm}$ ultrathin sections using a Reichert Ultracut-S microtome. Sections were placed onto copper grids and stained with lead citrate. The sections were examined using a 1200EX transmission electron microscope (JEOL). Images were recorded with an AMT $2 \mathrm{k}$ CCD camera at 20,000-30,000 $\times$ magnification.

Assessment of striatal DA fiber integrity and stereological counting. The $25 \mu \mathrm{m}$ free-floating sections were rinsed in PBS $(0.15 \mathrm{~m} \mathrm{NaCl}, 0.1 \mathrm{M}$ Tris- $\mathrm{HCl}, \mathrm{pH}$ 7.5) and endogenous peroxidase activity quenched with $0.3 \% \mathrm{H}_{2} \mathrm{O}_{2}$ in TBS for $30 \mathrm{~min}$ at room temperature. Unspecific protein binding was blocked with $10 \%$ normal goat serum in PBS containing $0.3 \%$ Triton X-100. Sections were incubated with rabbit TH (AB152, 1:2000, Millipore) for $48 \mathrm{~h}$ at $4^{\circ} \mathrm{C}$. Following 3 rinses with PBS, sections were incubated with secondary anti-rabbit (1:1000, Dianova 711-065152 ) in PBS containing 10\% normal donkey serum, washed, and subsequently transferred into ABC solution (1:500 in PBS; Vectastain Elite Kit, Vector Laboratories) for $1 \mathrm{~h}$ and visualized with DAB. Brain sections across a 4.8-3.5 interaural range were chosen, referring to the Paxinos and Franklin mouse brain atlas (Paxinos and Franklin, 2001). Sections from all genotypes were simultaneously stained and digitized using constant imaging settings (StereoInvestigator, MicroBrightField), and subsequent analyses were performed on a blinded basis. Images were converted to grayscale, and the mean gray value intensity was measured in the caudate/putamen $(\mathrm{CPu})$ and in the adjacent corpus callosum (cc) to correct for signal background. Mean gray values were converted to uncalibrated optical density (UOD) using Image $1.46 \mathrm{r}$ software (National Institutes of Health). The UOD of TH signal in the $\mathrm{CPu}$ was calculated by the formula $\mathrm{CPu}_{\text {final(UOD) }}=\mathrm{CPu}_{(\mathrm{UOD})}-\mathrm{cc}_{(\mathrm{UOD})}$, similar to a previously published study (Schlachetzki et al., 2014). For stereological counting, every fourth free-floating section of $40 \mu \mathrm{m}$ thickness, encompassing the full rostrocaudal extent of the substantia nigra (SN) was stained for TH (for $36 \mathrm{~h}$ ) as described above. This approach resulted in 9 or 10 sections in which the $\mathrm{SN}$ was identified. The number of TH-positive neurons in the $\mathrm{SN}$ pars compacta (SNpc) of one hemisphere was stereologically assessed using the optical fractionator principle and using the Stereo Investigator software (MicroBrightField). The ROI was outlined using a $2.5 \times$ objective and sampled with a $40 \times$ objective using a square optical frame (SNpc: $50 \times 50 \mu \mathrm{m})$ and sampling grid $($ SNpc: $60 \times 60$ $\mu \mathrm{m}$ ), with $2 \mu \mathrm{m}$ guard zones above and below the counting. The estimated coefficient of error (Gundersen, $\mathrm{m}=1$ ) ranged from 0.05 to 0.07 , and the estimated section thickness was $\sim 19 \mu \mathrm{m}$. The reported "total" number of TH-positive neurons is the number estimated by numberweighted section thickness multiplied by a factor of 2 , representing both hemispheres.

Experimental treatment design, quantification, and statistical analysis. The $3 \mathrm{~K}$ mice and WT $\alpha \mathrm{S}$ transgenic mice were administered $100 \mu \mathrm{g} / \mathrm{kg}$ DHED (Sigma-Aldrich) dissolved in corn oil (Sigma-Aldrich) through daily subcutaneous injections for up to $90 \mathrm{~d}$, and all animals were sacrificed at age 10 months. Age- and sex-matched $3 \mathrm{~K}$ and WT control mice were injected with the vehicle (Sham). Behavioral testing was conducted before treatment (pre) and at $30 \mathrm{~d}$ (data not shown) and at $90 \mathrm{~d}$ of treatment as indicated. Experimental details specific for behavioral testing are included in behavior testing below. Details regarding each statistical test, biological sample size $(n)$, and $p$ value can be found in the corresponding figure legends. All data are represented as mean \pm SEM. SEM represents variance within a group. In all experiments, the geno- 
a

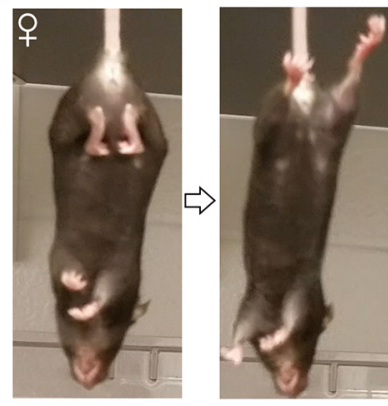

d

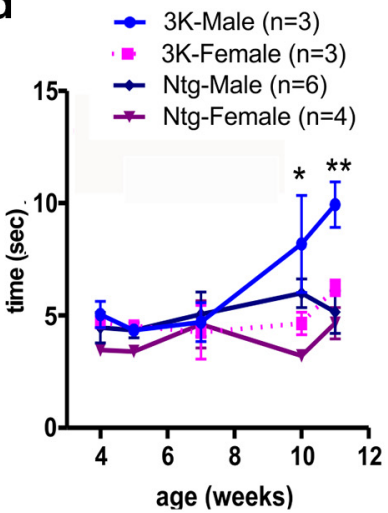

b

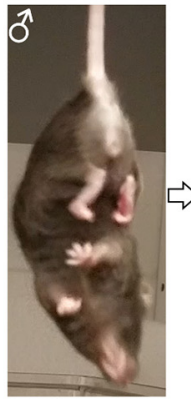

e

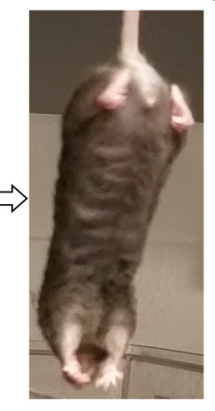

pole test
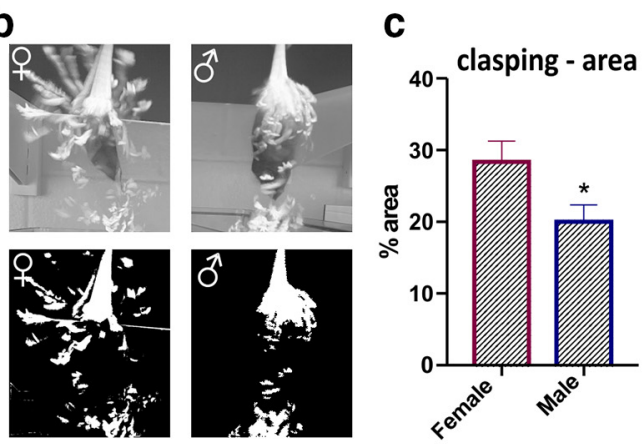

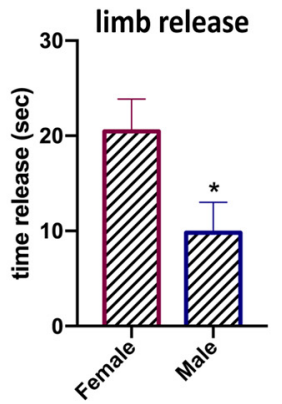

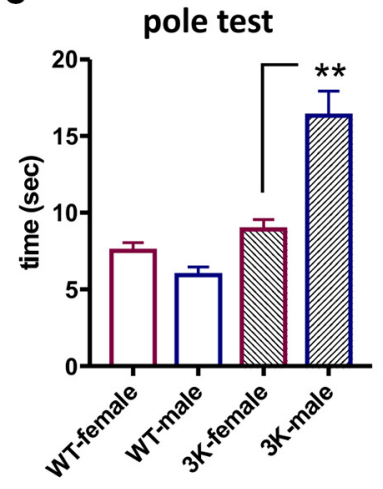
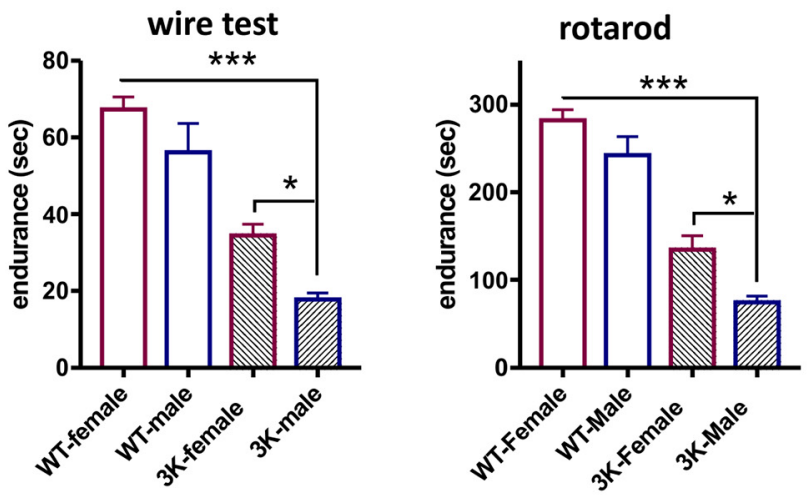

Figure 1. Sex differences of progressive motor deficits in $3 \mathrm{~K} \alpha \mathrm{S}$ tg mice. $\boldsymbol{a}$, Limb clasping in $3 \mathrm{~K}$ female versus (vs.) $3 \mathrm{~K}$ male $\alpha \mathrm{S}$ tg mice at 6 months. $\boldsymbol{b}$, Stacked images to assess rigor of limbs in $3 \mathrm{~K}$ female and male mice at 6 months by videography and ImageJ software (representative images are shown).c, Quantification of time hindlimbs were released from the clasped (= flexed) position and of percentage area hindlimb coverage in $\boldsymbol{b}$ (see Materials and Methods) ( $n=6$ each group). $\boldsymbol{d}$, Longitudinal quantification of time to descend the pole in mice $4-12$ weeks of age. $\boldsymbol{e}$, Left, Quantification of time to descend the pole for 6-month-old mice. Middle, Quantification of muscle tone-related endurance of $3 \mathrm{~K}$ males and females in the 4-limb wire-hanging test. Right, Quantification of fine motor and balancing skills in a $4-40 \mathrm{rpm}$ accelerating rotarod test. No significant behavioral impairments or sex-related changes are observed in age-matched WT controls. Data are mean \pm SEM. ${ }^{*} p<0.05 ;{ }^{* *} p<0.01 ;{ }^{* * *} p<0.001$; unpaired two-tailed $t$ test $(\boldsymbol{c})$; or two-way ANOVA post Tukey $(\boldsymbol{d}, \boldsymbol{e})$.

types can be found in the corresponding legends. Data were collected and processed side by side in randomized order for all experiments. Behavioral and histological tests were routinely performed blind to the conditions of the experiments. Unpaired, two-tailed $t$ tests were used for comparison between two groups, with $p \leq 0.05$ considered significant. For all comparisons involving multiple variables, one-way ANOVA or two-way ANOVA was performed followed by post hoc test for multiple comparisons using $p \leq 0.05$ for significance. For all experiments, 3-6 (biochemistry, histology) and 5-12 (behavior) animals per experiment were used, with the number per group stated in each figure legend. Additional bar graphs have been included to show the appropriate statistical information (mean $\pm \mathrm{SEM}$ ). All statistical analyses were performed using Prism (GraphPad).

Behavioral testing. All behavioral testing has been conducted as previously described (Nuber et al., 2018). Briefly, groups of male and female mice were prepared for behavioral analyses by daily handling by the investigator 1 week before behavioral assessment. Unless otherwise noted, all behavioral trials were assessed in a blind manner.

Clasping. For clasping analyses, mice were held by their tails and analyzed for their behavior for up to $30 \mathrm{~s}$. To measure ability of limb release from the flexed (=clasped) position in 6-month-old 3K male and female mice ( $n=6$ per group), we used short-term ( $30 \mathrm{~s}$ ) video recording of mice and subsequent stacking of $\sim 60$ frames. The layers were converted to a smart object and then to the stack mode "maximum" to capture the paws and to sum the limb movements in a single frame image using Photoshop software (Adobe). This method allowed evaluation of area covered by the limbs, which were inverted for clarity. The percentage area of limb coverage was evaluated by ImageJ pixel intensity measurement.

Pole test. Mice were placed on top of a $50 \mathrm{~cm}$ vertical pole (all-thread metal rod) with a diameter of $1 \mathrm{~cm}$ and tested for their ability to descend the pole. Maximal duration time was set to $60 \mathrm{~s}$ to avoid exhaustion. The pole test consisted of 3 consecutive trials (climbing down) and average times to "climb down" were calculated for each mouse.
Gait scan. To assess motor function and coordination in walking mice, automated gait analysis was performed using Treadscan (Cleversys). Gait patterns of 10 month-old mice were measured for $25 \mathrm{~s}$ at a speed of 15.7 $\mathrm{cm} / \mathrm{s}$ on a transparent running belt illuminated by a LED light and reflecting footprints captured by a video camera positioned underneath the walkway.

Wire hang test. Mice were placed in the center of a linear wire with all 4 paws and tested for their ability to hold onto it. Maximal duration time was set to $90 \mathrm{~s}$ to avoid exhaustion. The wire test consistent of 3 consecutive trials and average endurance time were calculated for each mouse.

Rotarod. Motor coordination and motor skill learning were evaluated using an accelerating rotarod (Ugo Basile), and time spent on the rod was recorded. The first day consisted of a habituation trial at constant speed ( $4 \mathrm{rpm}$ for $5 \mathrm{~min}$ ), followed by two trials of 4-40 rpm progressive acceleration within 5 min for 5 consecutive days, including 2 trials each day. On the next $2 \mathrm{~d}$, the mice were tested only on the accelerating trials (4-40 $\mathrm{rpm}, 5 \mathrm{~min}$ ). An intertrial pause of at least $1 \mathrm{~h}$ was applied to avoid fatigue and stress, and a maximum cutoff of 5 min was used. Motor coordination was evaluated by comparing the mean latency to fall over the 3 consecutive days between groups and against their pre-treatment baseline performance.

\section{Results}

The tetramer-to-monomer shift caused by the $3 \mathrm{~K}$ mutation is associated with a progressive motor syndrome with earlyonset and higher prevalence in males

We previously observed $3 \mathrm{~K} \alpha \mathrm{S}$ transgenic mice develop behavioral changes that included abnormal gait due to the lack of coordinated limb movement and gradually worsening head and body tremor within the first 3-6 months after weaning $(\sim 1$ month) (Nuber et al., 2018). By the age of 6 months, all 3K mice had a stiff, uncoordinated gait, which was preceded by hindlimb 

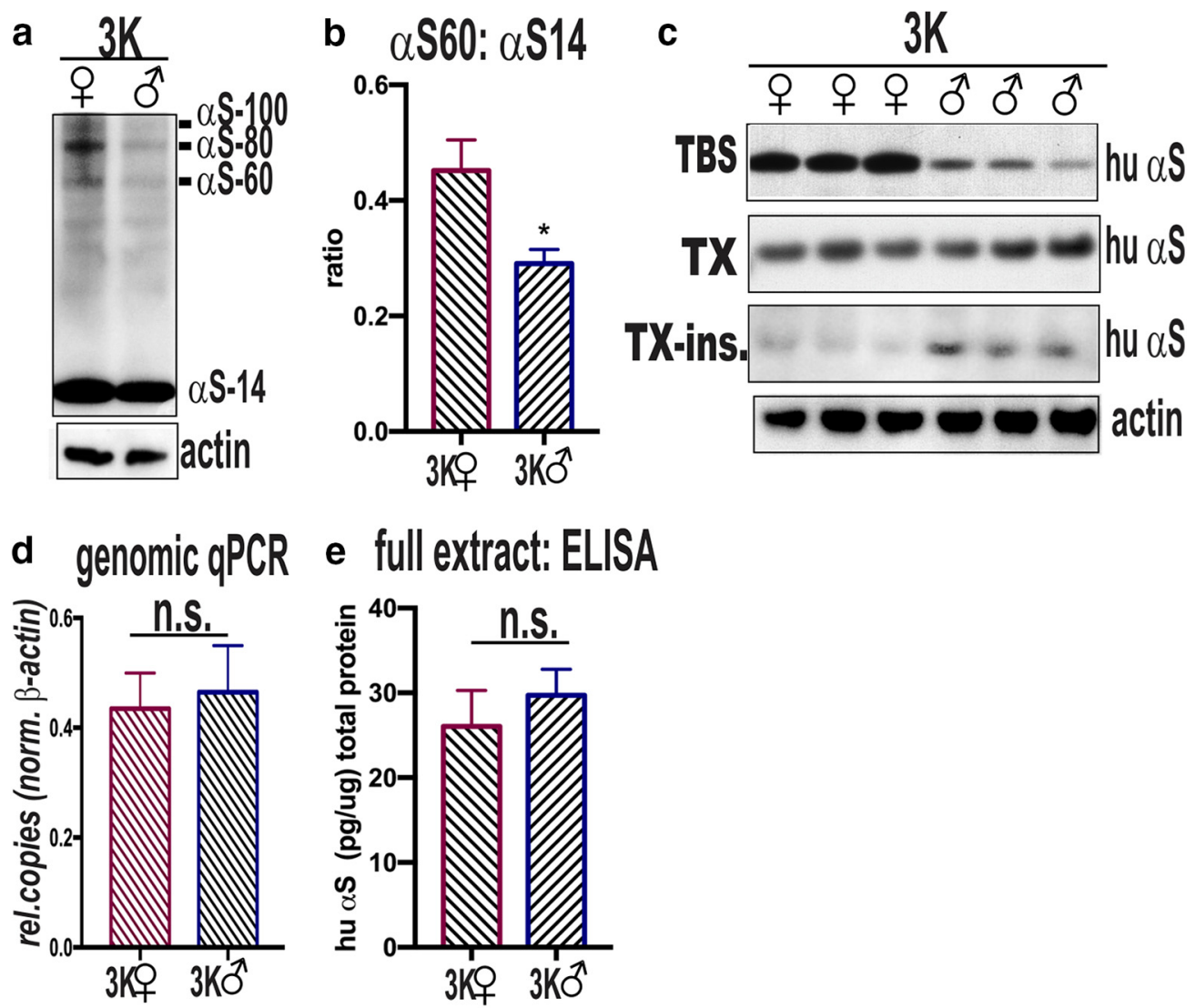

\section{e full extract: ELISA}

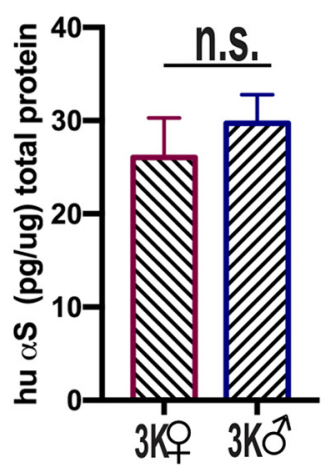

Figure 2. Sex differences in $\alpha$ S solubility and T:M ratio. $\boldsymbol{a}$, Intact cell-crosslinking of $\alpha$ S in cortical brain bits from 3K female and 3K male mice. Syn 1 ab detects monomeric ( $\alpha$ S14) and tetrameric $(\alpha S 60) \alpha S$ and probable conformers of the tetramer $(\alpha S 80, \alpha S 100)$ (Dettmer et al., 2013). Actin serves as a control for loading. Representative WB of T:M ratio in $3 K$ female vs. male. $\boldsymbol{b}, \mathrm{Quantitative}$ WBs of $\alpha$ S monomers ( $\sim 14 \mathrm{kDa}$ ) and tetramers ( $\sim 60 \mathrm{kDa}$ ) reveal an increased T:M ratio in $3 \mathrm{~K}$ females vs. $3 \mathrm{~K}$ males ( $n=3$ mice per genotype run in 3 independent experiments). $c$, WBs of (non-cross-linked) sequential extractions of TBS-soluble (cytosolic), Triton X-100-soluble (membrane), and Triton X-100-insoluble full brain homogenates (15G7: hu $\alpha$ S) reveal increased soluble and less insoluble $\alpha$ S in $3 \mathrm{~K}$ females vs. 3K males. $\boldsymbol{d}$, Relative copy numbers by qPCR of genomic DNA with values normalized to actin. $\boldsymbol{e}$, hu-specific $\alpha S$ ELISA shows equal $\alpha$ S protein levels in cortical brain homogenates of 6-month-old 3K male and 3K female mice $(n=3)$. n.S., non-significant; ${ }^{*} p<0.05$ (unpaired two-tailed $t$ test).

clasping that began at $\sim 3-4$ months. While clasping is observed in both males and females by 6 months, $3 \mathrm{~K}$ females more frequently extended their limbs from the flexed position than males (Fig. 1a). The stacked (superimposed) images of $\sim 30 \mathrm{~s} / 80$ frames were converted to the stack mode "maximum" to highlight limb movement in a single frame image. The calculated paw area covered in female vs. male $3 \mathrm{~K}(p=0.050)$ by limb release $(p=0.045)$ suggests less muscle rigor in female $3 \mathrm{~K}$ mice (Fig. $1 c$ ). In particular, longitudinal testing of newly weaned $3 \mathrm{~K}$ mice vs. Ntg littermates showed $3 \mathrm{~K}$ females to notably delay the raise in time to climb down the pole that appeared more robustly in male $3 \mathrm{~K}$ mice starting at 10 weeks of age (Fig. 1d). Two-way ANOVA confirmed a significant interaction between sex and genotype of the longitudinal pole testing $\left(F_{(12,60)}=2.25, p=0.02\right)$. Post hoc multiple comparisons revealed significant decrease in time to climb the pole in female vs. male $3 \mathrm{~K}$ mice starting at 10 weeks of age ( 10 weeks: $p=0.05 ; 11$ weeks: $p=0.0064)$. At 6 months of age, $3 \mathrm{~K}$ females showed a consistent less increase in time to climb down the pole (Fig. 1e) (relative percentages: female $3 \mathrm{~K}$ vs WT: $18 \pm 19 \%$; male $3 \mathrm{~K}$ vs WT: $76 \pm 27 \%$ ), longer endurance in the 4 -limb wire hanging test (Fig. 1e, middle) (female $3 \mathrm{~K}$ vs WT: $-50 \pm 4.2 \%$; male $3 \mathrm{~K}$ vs WT $-68.4 \pm 3 \%$ ), and an increased ability to maintain balance while walking on a slowly accelerating rotarod (Fig. 1e, right) (female $3 \mathrm{~K}$ vs WT: $-52 \pm 6 \%$; male $3 \mathrm{~K}$ vs WT: $-70 \pm 2.8 \%)$. Two-way ANOVA confirmed a significant interaction between sex and genotype for pole testing $\left(F_{(1,19)}=\right.$
10.59, $p=0.0042)$ and wire performance $\left(F_{(1,19)}=4.2, p=\right.$ $0.050)$. Accelerating rotarod test showed a nonsignificant interaction, however, there were significant main effects on both sex $\left(F_{(1,19)}=14.5, p=0.0012\right)$ and genotype $\left(F_{(1,19)}=146, p<\right.$ $0.0001)$. In all cases, multiple comparison post hoc tests showed improved motor performances by female sex in $3 \mathrm{~K}$ mice (pole: $p=0.004$; wire: $p=0.03$; rotarod: $p=0.016$ ). In contrast, matched overexpression of WT hu $\alpha \mathrm{S}$ did not induce clasping or other motor deficits as shown previously (Nuber et al., 2018), and female and male WT mice were not different from each other in all motor tests (Fig. $1 e ; p>0.1$ ).

\section{Female sex decreases shift of $\alpha S$ tetramers toward excess} monomers and the $\alpha \mathrm{S}$ membrane association

To investigate sex-related differences on $\alpha \mathrm{S}$ homeostasis in $3 \mathrm{~K}$ mice, we first assessed tetramerization in $3 \mathrm{~K}$ female and male mice using our previously described method to trap the cell-lysissensitive tetramers by intact-cell crosslinking of fresh, minced cortical brain tissue bits with the cell-penetrant crosslinker DSG (Dettmer et al., 2013, 2015).

Quantitative WBs of cortical extracts indicated an increase in $\alpha$ S60 (and related multimers $\alpha$ S80 and $\alpha$ S100) and lower $\alpha$ S14 monomer signals in female vs. male $3 \mathrm{~K}$ brain (Fig. $2 a$ ). Evaluating the relative level between $\alpha \mathrm{S} 60$ tetramers and $\alpha \mathrm{S} 14$ monomers, we found a significant increase in the tetramer-to-monomer ratio (T:M) in female $3 \mathrm{~K}$ brain $(p=0.03)$ (Fig. $2 b)$. Sequential extrac- 

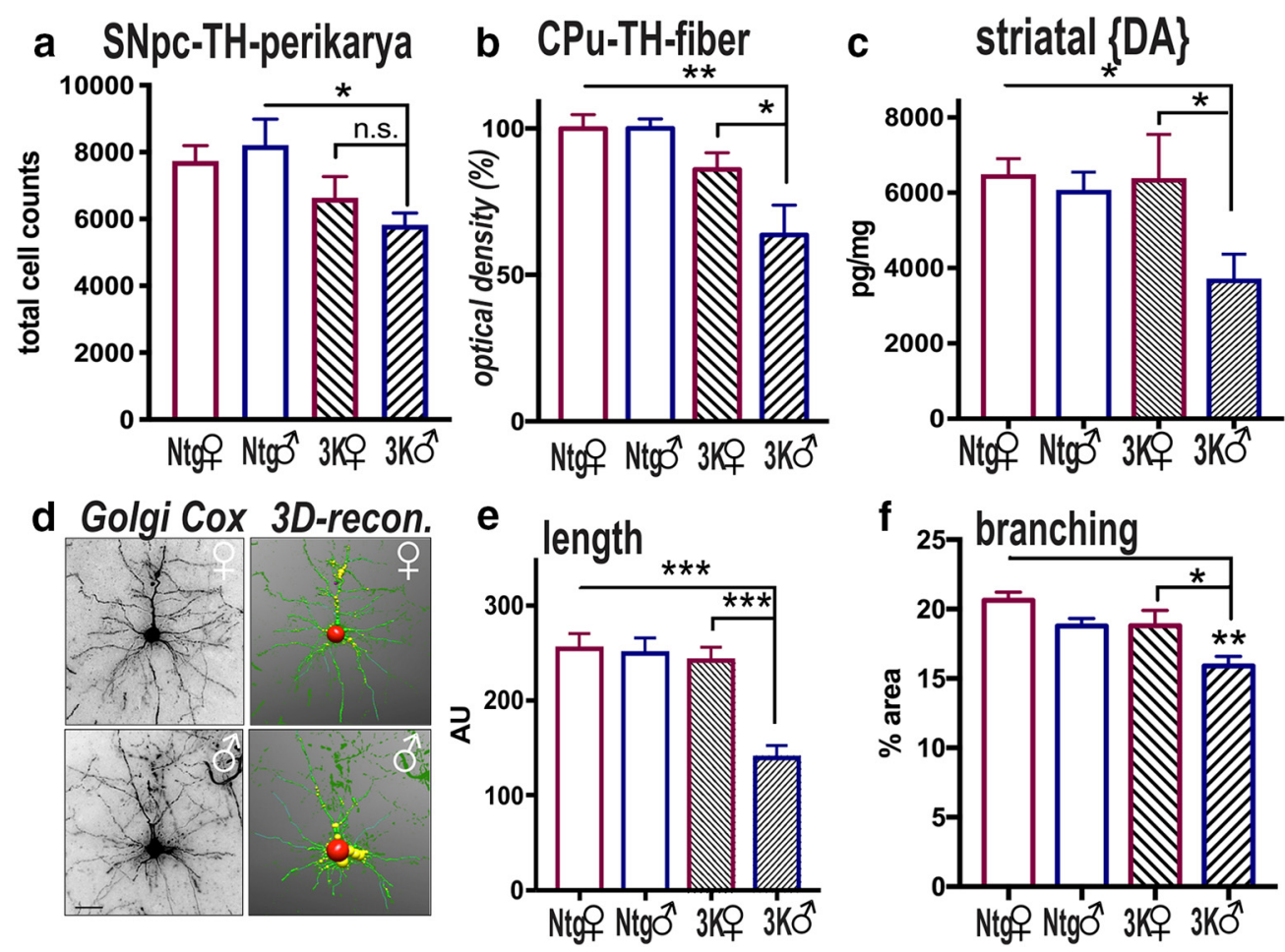

Figure 3. Sex differences in cortical and dopaminergic neurodegeneration in 6-month-old 3K mice. $\boldsymbol{a}$, Unbiased stereological counting determined the number of $\mathrm{TH}^{+}{ }^{+}$neurons in the SNpc of 6-month-old mice. $\boldsymbol{b}$, Relative TH optical density (total of 18 sections each group) was analyzed in the CPu. $\boldsymbol{c}$, HPLC assay of striatal dopamine in 6-month-old male and female 3K mice vs. Ntg littermates ( $\boldsymbol{a}-\boldsymbol{c}$ : Ntg, $3 K n=5$ each sex). $\boldsymbol{d}$, Using NeuronStudio software for automatic tracing of Golgi Cox-impregnated neuritic profiles for (e) estimating fiber length ( $n=10$ traced neurons) or $(\boldsymbol{f})$ percentage area covered ( $n=10$ fields) of cortical sections ( $n=3$ mice per age and genotype). Data are mean \pm SEM. Two-way ANOVA, post Tukey: $n$.s., non-significant; ${ }^{*} p<0.05 ; * * p<$ $0.01 ; * * * 0001$. Scale bar: $\boldsymbol{d}, 25 \mu \mathrm{m}$.

tions of full homogenates revealed an increased buffer-soluble (cytosolic) $\alpha \mathrm{S}$, and fewer Triton X-100-solubilized (membraneassociated) $\alpha \mathrm{S}$ and Triton $\mathrm{X}-100$-insoluble (aggregated) $\alpha \mathrm{S}$ in female vs. male $3 \mathrm{~K}$ mouse brain (Fig. $2 c$ ). We observed the increase in $\alpha \mathrm{S}$ solubility and tetramerization despite a similar hu $\alpha \mathrm{S}$ expression level in female vs. male $3 \mathrm{~K}$ as determined by genomic qPCR for the relative amount of transgene copy numbers (Fig. $2 d$ ) and a hu $\alpha$ S-specific ELISA (Fig. 2e).

\section{Increase in $\alpha \mathrm{S}$ T:M and solubility associates with increased} cortical and DAergic neurite complexity in $3 \mathrm{~K}$ females

To assess whether the increased $3 \mathrm{~K} \alpha \mathrm{S}$ tetramerization and solubility as well as the associated motor phenotype correlates with changes in DAergic integrity, we first counted TH-immunopositive $\left(\mathrm{TH}^{+}\right)$neurons of $3 \mathrm{~K}$ mice vs. Ntg littermates (Ntg females: $7735 \pm 463.9$; Ntg males: $8216 \pm 768.1$; $3 \mathrm{~K}$ females: $6641 \pm 727 ; 3 \mathrm{~K}$ males: $5825 \pm 358.2$ ) (Fig. 3a). Two-way ANOVA revealed a significant main effect of genotype $\left(F_{(1,16)}=8.307, p=\right.$ 0.01 ), although there was no significant interaction between sex and genotype for the nigral TH counts. Multiple comparisons showed significantly reduced DAergic neurons only in male Ntg vs. $3 \mathrm{~K}$ (female Ntg vs $3 \mathrm{~K}: p=0.55$; male Ntg vs $3 \mathrm{~K}: p=0.043$ ). Females were previously reported to have an improved capacity to recover from toxin-induced PD compared with males and to preserve the striatal function (Gillies et al., 2014). Thus, we next quantified reduction of $\mathrm{TH}^{+}$axons and their terminals. We analyzed the dorsal striatum $(\mathrm{CPu})$, which is rich in projections from the DAergic neurons of the SNpc (Fig. 3b). Notably, 6-month-old 3K females showed fewer $\mathrm{TH}^{+}$fiber immunoreactivity than the age-matched $3 \mathrm{~K}$ males (relative percentages: female $\mathrm{Ntg}$ vs $3 \mathrm{~K}:-14 \pm 4 \%$; male $\mathrm{Ntg}$ vs $3 \mathrm{~K}$ : $-33 \pm 2.8 \%$ ). Two-way ANOVA confirmed a significant interac- tion between sex and genotype $\left(F_{(1,32)}=4.897, p=0.03\right)$. Post hoc multiple comparisons showed increased $\mathrm{TH}^{+}$densities in female vs. male $3 \mathrm{~K}$ mice $(p=0.02)$. No changes were detected between female and male Ntg mice.

In addition to $\mathrm{TH}^{+}$striatal terminals, the corresponding DA levels were measured in mouse brains (Fig. $3 c$ ). There was a main effect on the genotype $\left(F_{(1,17)}=4.7, p=0.04\right)$, and multiple comparisons showed a significant decrease in DA of $\sim 27 \%$ only in $3 \mathrm{~K}$ males (female Ntg vs $3 \mathrm{~K}: p=0.18$; male Ntg vs $3 \mathrm{~K}: p=$ 0.017 ), and paired comparisons revealed more DA in female vs. male $3 \mathrm{~K}$ mice $(p=0.025)$, but there was no significant interaction between sex and transgene ( $p=0.137$ ) (Fig. 3c).

Since degeneration of $\mathrm{TH}^{+}$striatal nerve terminals affects cortical neuron morphology (Solis et al., 2007), we traced the pyramidal neurons localized within the somatosensory and motor cortex region and generated a 3D reconstruction of the dendritic profile using NeuronStudio Software (see Materials and Methods). We found that $3 \mathrm{~K}$ females showed relatively long cortical neuronal fibers. Two-way ANOVA analysis of the singletraced neurons ( $n=10$ per group) confirmed a significant interaction $\left(F_{(1,36)}=12.87, p=0.001\right)$ and a main effect of genotype $\left(F_{(1,36)}=20.76, p<0.001\right)$ and $\operatorname{sex}\left(F_{(1,36)}=15.43, p=\right.$ $0.0004)$. Paired comparisons showed increased neuritic length in female vs. male $3 \mathrm{~K}$ mice $(p<0.001)$ (Fig. 3e). No differences were detected between female and male Ntg controls. In addition, evaluation of the dendritic arborization showed higher fiber complexity in $3 \mathrm{~K}$ females (Fig. $3 f$ ) as measured in percentage area covered (Ntg females: $21 \pm 0.59 \%$; Ntg males: $19 \pm 0.53 \%$; $3 \mathrm{~K}$ females: $19 \pm 0.8 \%$; $3 \mathrm{~K}$ males: $16 \pm 0.7 \%)$. Two-way ANOVA confirmed main effect on sex $\left(F_{(1,32)}=13.03, p=0.0010\right)$ and genotype $\left(F_{(1,32)}=12.7, p=0.0012\right)$. The paired comparison 
revealed a significant increase in percentage area covered in female vs. male $3 \mathrm{~K}$ mice $(p=0.03)$. In summary, the data suggest that female sex preserved neurite fiber integrity in $3 \mathrm{~K}$ mice.

\section{DHED treatment produces markers of estrogenic effects in $3 \mathrm{~K}$ brain}

Several studies suggest that estrogens delay PD onset and protect DAergic neurite fiber integrity (Gillies et al., 2014), providing a likely explanation for the observed preserved DAergic (Fig. 3a-c) and cortical fiber densities (Fig. $3 d-f$ ) and associating with less motor impairments in $3 \mathrm{~K}$ female vs. $3 \mathrm{~K}$ males (Fig. $1 a-c$ ). However, clinical use of estrogen therapy remains controversial due to the observed adverse peripheral effects. Recent studies investigated the benefits of treatment with DHED, a brain-selective (Prokai et al., 2015) prodrug of $17 \beta$-estradiol, and found it effective in a rodent stroke model (Prokai et al., 2015) as well as in female (Tschiffely et al., 2016) and male (Tschiffely et al., 2018) AD mice. We treated 7-month-old $3 \mathrm{~K}$ and WT male mice at a dose of $100 \mu \mathrm{g} / \mathrm{kg}$ per day for $90 \mathrm{~d}$ (Fig. $4 a)$. To further validate the DHED delivery to the brain (Prokai et al., 2015), we measured its subsequent conversion to estrogen using a highly sensitive ELISA (Fig. $4 b)$, previously shown to detect $17 \beta$ estradiol in male and female mouse brain (Chen et al., 2013; Zhang et al., 2014; Lu et al., 2019). The DHED treatment significantly increased brain estradiol concentration in male mice $(p=0.002)$ (Fig. $4 b$, left). As expected (Prokai et al., 2015), there was no detectable effect in plasma by the DHED treatment (data not shown). We also found DHED treatment to increase brain $17 \beta$-estradiol level in female mice (Fig. $4 b$, middle). One-way ANOVA confirmed significant effects by DHED treatment $(F=6.117 ; p=0.0047)$, but multiple comparisons of the fold change showed significance only in male brain ( $p$ $=0.006$ ) (Fig. $4 b$, right). The less pronounced change in female brain is likely due to the overall higher estradiol level. Additional variability due to the estrous cycle may mask the DHED-induced estradiol elevation in female mouse brain.

Estrogen actions are mediated by estrogen receptors (i.e., estrogen receptor $\alpha$ $[\operatorname{ER} \alpha]$ ), and estradiol was shown to temporarily upregulate $\mathrm{ER} \alpha$ in cell culture and in mouse brain (Liu and Shi, 2015). Our histo-staining confirmed expression of $\mathrm{ER} \alpha$ in cortical regions of female and male $3 \mathrm{~K}$ mice, and in cells accumulating pSER-positive aggregates (Fig. 4c). Partic- a

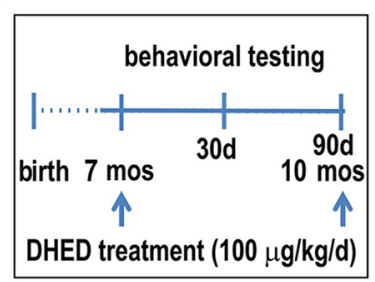

b $17 \beta$-estradiol

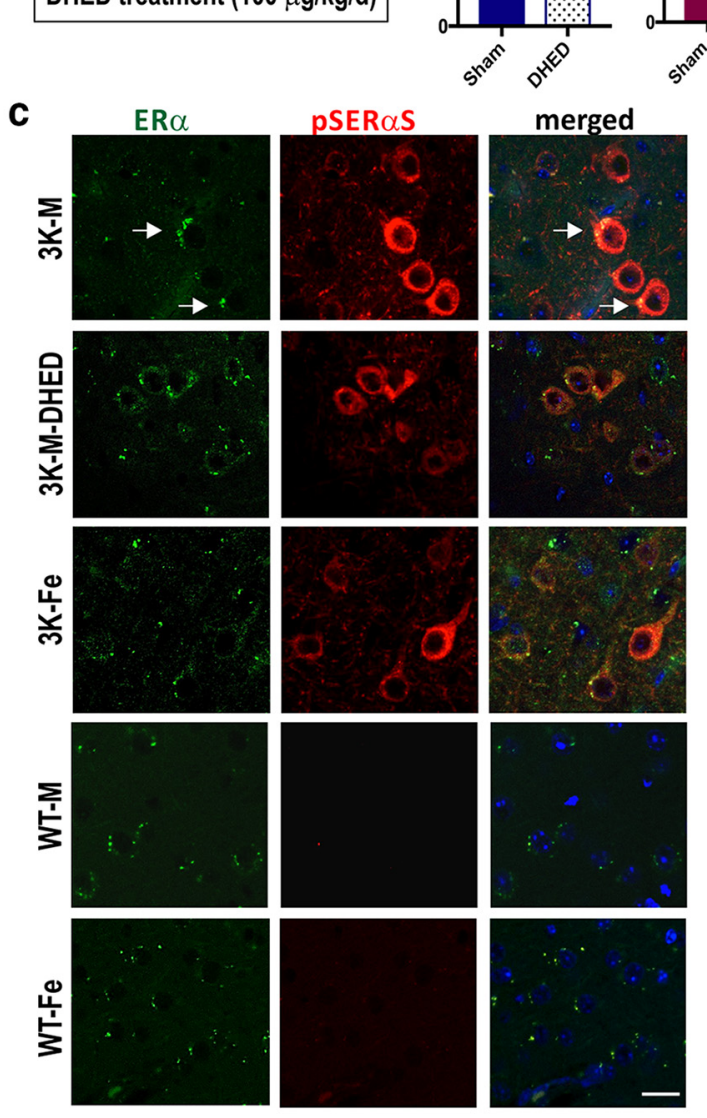

d

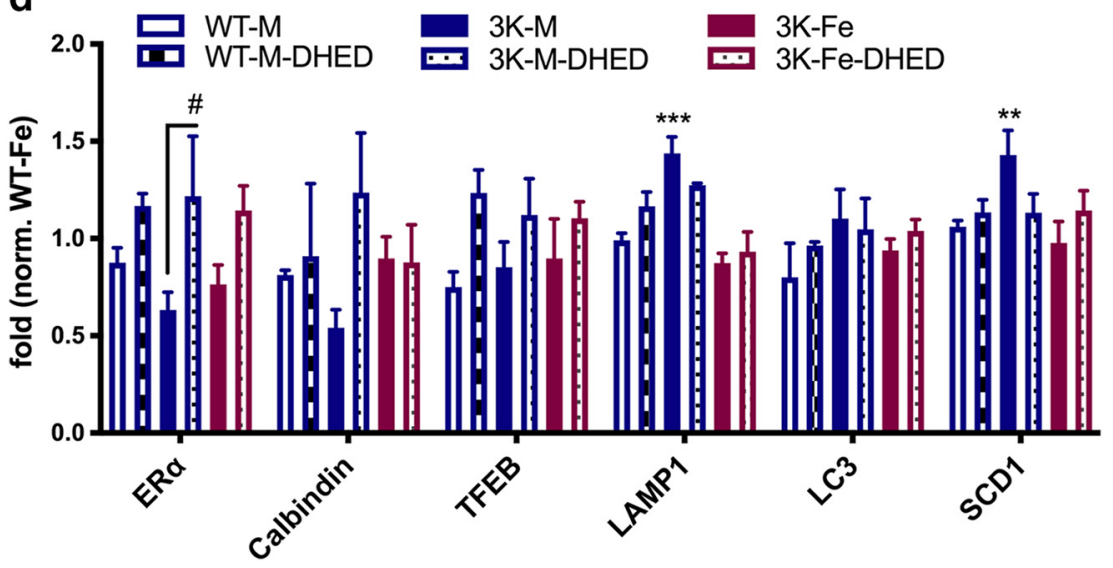

Figure 4. DHED treatment increases brain estradiol and markers of estrogenic effects. $\boldsymbol{a}$, Mice treatment and analysis paradigm. For studying therapeutic effects, 7 -month-old (symptomatic) $3 \mathrm{~K}$ males were injected subcutaneously for 90 consecutive days with $100 \mu \mathrm{g}$ DHED, a brain-selective estrogen-prodrug (Prokai et al., 2015). Motor performance was recorded at baseline, after $30 \mathrm{~d}$, and finally assessed after 90 d. $\boldsymbol{b}$, High-sensitive ELISA measurement of estradiol level in brain extracts after DHED treatment shows significantincrease in male brains. Note the general higher $17 \beta$-estradiol level in female mice.c, Confocal microscopy of brain sections from (vehicle-treated) male 3K-Sham and 3K-DHED mice, and 3K female mice and WT female controls labeled for ER $\alpha$ in cells displaying pSer129- $\alpha$ S (red) aggregates as indicated. $\boldsymbol{d}$, Expression data for representative (selected) estrogen-responsive and autophagy-relevant genes. Data are mean \pm SEM. ${ }^{* *} p<0.01$ vs. DHED ( $\boldsymbol{b}$, middle, unpaired two-tailed $t$ test; $\boldsymbol{b}$, right, one-way ANOVA post Tukey). ${ }^{* *} p<$ 0.01; ${ }^{* * *} p<0.001 ; \#<<0.05$; vs. DHED (d, two-way ANOVA post Tukey). Scale bar: c, $20 \mu \mathrm{m}$. 


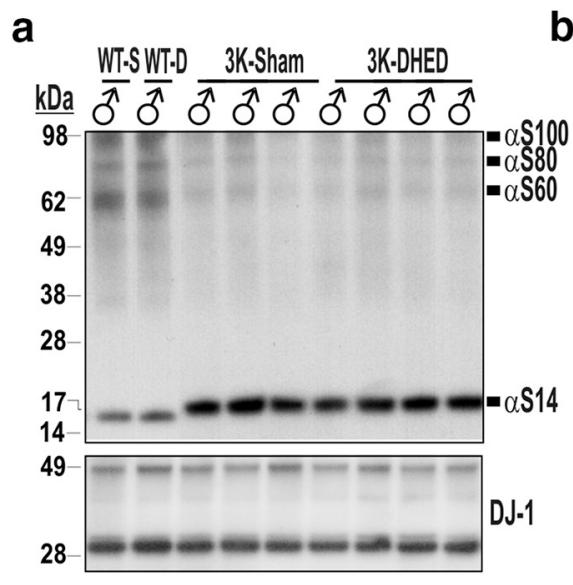

d

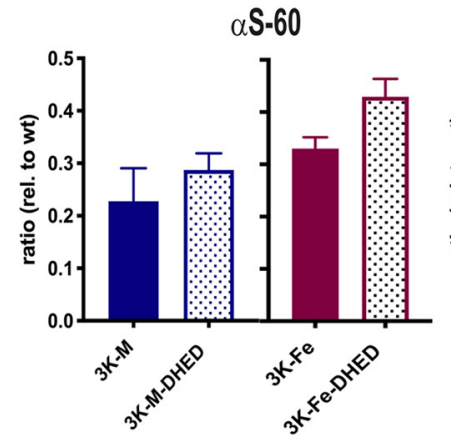

b

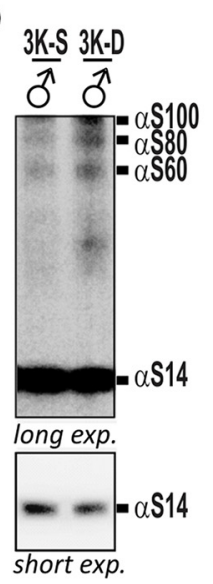

C

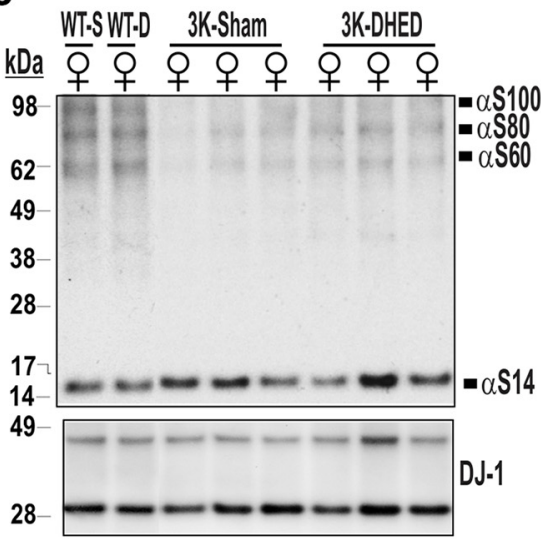

$\alpha \mathrm{S}-14$
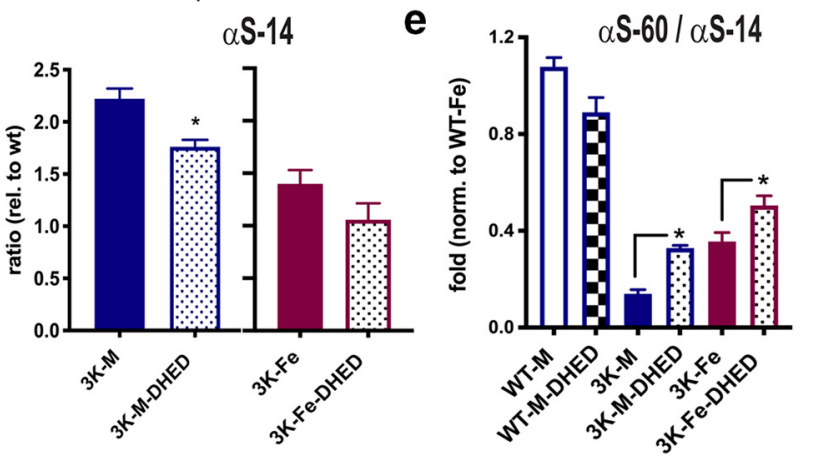

Figure 5. DHED treatment increases T:M ratio in 3K mice. $\boldsymbol{a}$, Intact cell-crosslinking of $\alpha$ S in cortices of male and (c) female $3 \mathrm{~K}$ and WT mice treated with either vehicle (Sham) or DHED. $\boldsymbol{b}$, Higher or lower blot exposure time shows both increase in multimeric and decrease in monomeric $\alpha \boldsymbol{S}$. $\boldsymbol{d}$, Quantitative WBs of $\alpha \mathrm{S}$ monomers ( $\sim 14 \mathrm{kDa}$ ) and tetramers ( $\sim 60 \mathrm{kDa}$ ) reveal a trend to increase tetramer level and a significant reduction of monomeric $\alpha$ S level in $3 \mathrm{~K}$ males and to similar level of $3 \mathrm{~K}$ females (each normalized to WT condition). Separation of graphs due to blots being run at different time points. $\boldsymbol{e}$, Stepwise increase in T:M ratio in DHED treated brain of either male or female $3 \mathrm{~K}$ mice toward level of normal WT mice. Data are mean \pm SEM. $\boldsymbol{d}$, ${ }^{*} p<0.05$ (tw0-tailed $t$ test). $\boldsymbol{e}^{*}{ }^{*} p<0.05$ (two-way ANOVA post Tukey).

ularly, DHED treatment and female sex improved the redistribution of the ER $\alpha$ in cells positive for pSER-modified $\alpha$, shown by the more finely immunoreactive puncta (Fig. $4 c$ ). The pSER aggregates were far less common in the age- and expressionmatched WT tg brains (Fig. 4c, bottom), as we previously showed (Nuber et al., 2018).

RT-PCR of RNA extracts generated $2 \mathrm{~h}$ after the final dosing showed an expected increase by DHED treatment in $3 \mathrm{~K}$ males of previously described genes that are upregulated by estradiol: $\mathrm{ER} \alpha$ (Liu and Shi, 2015) and calbindin (Stuart et al., 2001), or downregulated gene expression level, such as the fatty acid-desaturase SCD-1 (Paquette et al., 2008) (Fig. 4d). Two-way ANOVA revealed a significant interaction between genotype and treatment for $\operatorname{ER} \alpha\left(F_{(3,38)}=3.151, p=0.04\right)$ and for SCD-1 $\left(F_{(3,38)}=3.987, p=0.01\right)$ and the lysosomal membrane protein LAMP-1 $\left(F_{(3,38)}=4.37, p=0.009\right)$, and a main effect for transgene for LAMP-1 $(p<0.001)$ and SCD-1 $(p<0.001)$. A significant main effect for treatment was found for $\operatorname{ER} \alpha\left(F_{(1,38)}=17.25, p=0.0002\right)$, and for calbindin $\left(F_{(1,38)}\right.$ $=5.206, p=0.03)$, further confirming estrogen-action by DHED. Post hoc multiple comparisons showed a significant increase of the reduced ER $\alpha$ level by DHED in $3 \mathrm{~K}$ males ( $p=$ $0.05)$. We also observed DHED-3K males to trend toward the significant reduction of LAMP-1 and SCD-1 gene expression, that was significant between $3 \mathrm{~K}$ males and either female $3 \mathrm{~K}$ or WT mice $(p<0.01)$. We found no significant between group differences in WT mice.
DHED treatment increases the $\alpha S \mathrm{~T}: \mathrm{M}$ ratio and reduces aggregate-prone monomers by autophagy clearance

As a first step in determining the effects of increased estrogen level in brain on PD-like neuropathology in $3 \mathrm{~K}$ mice, we assessed the $\alpha \mathrm{S}$ T:M ratio by intact-cell crosslinking of minced cortical brain tissue. The treatment with DHED increased $\alpha \mathrm{S} 60$ (tetramers) and decreased $\alpha \mathrm{S} 14$ (monomer) signals (Fig. $5 a$; see higher exposure in Fig. 5b). Quantifying the relative amounts showed a tendency of increased tetramers $(\alpha S 60)$ and a significant reduction of $\alpha \mathrm{S}$ monomers $(\alpha \mathrm{S} 14)$ (Fig. $5 a$, quantified in Fig. $5 d$ ) in male $3 \mathrm{~K}$ mice by DHED treatment similar to the level detected in female $3 \mathrm{~K}$ mice (Fig. $5 c, d$ ). Quantifying the relative T:M ratio between groups confirmed DHED treatment to increase $\alpha \mathrm{S}$ tetramerization in a stepwise pattern in $3 \mathrm{~K}$ males and $3 \mathrm{~K}$ females toward the physiological level of motorically normal WT brain (Fig. 5e).

We previously detected excess $\alpha \mathrm{S}$ monomers to coaggregate with lysosomal vesicles (Nuber et al., 2018), and such abnormalities are a common feature of PD (Kett and Dauer, 2016). Also, previous neuropathological analyses described accumulations of such vesicles close to (Watanabe et al., 1977; Kosaka, 1978; Hayashida et al., 1993) or as part of (Forno, 1996) hu LBs, and their sizes have been postulated to increase in early LB-type pathology (Kuusisto et al., 2003). Our former quantification showed a significant and age-dependent increase in the inclusion sizes of pSER $\alpha$ S aggregates that costained with lysosomal vesicle marker LAMP-1 in $3 \mathrm{~K}$ mice. Thus, to further investigate the ef- 
a
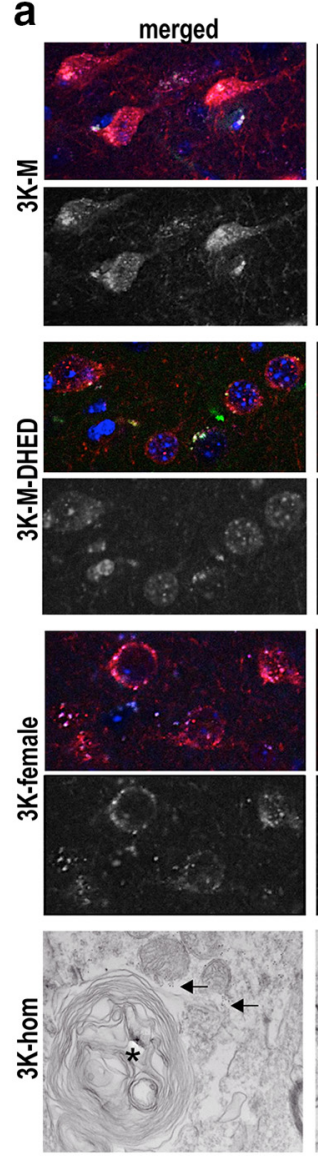

C

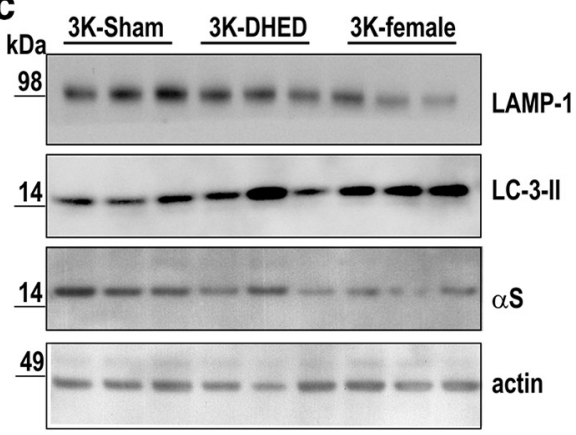

pSER129
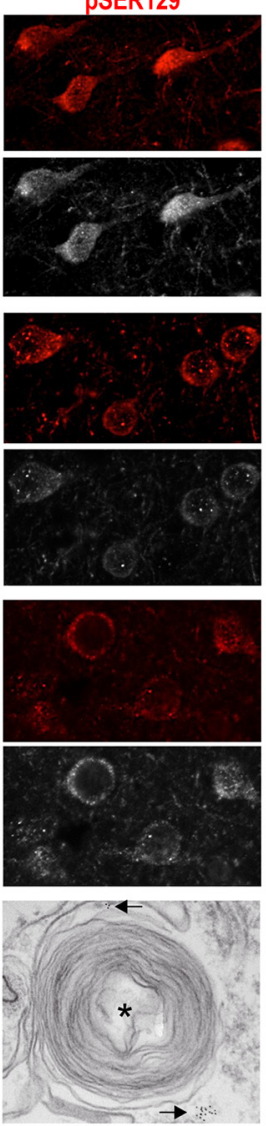

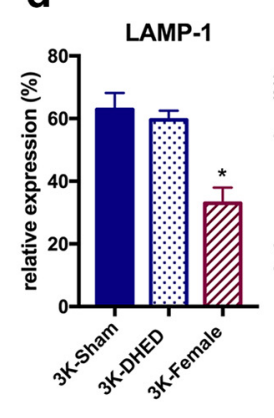

LAMP-1
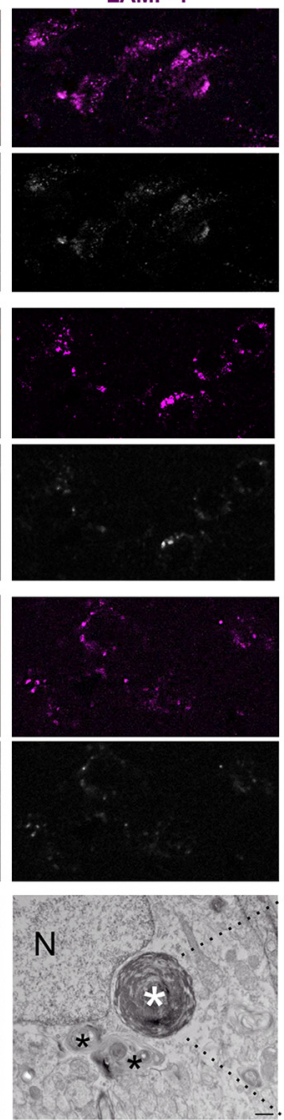

d
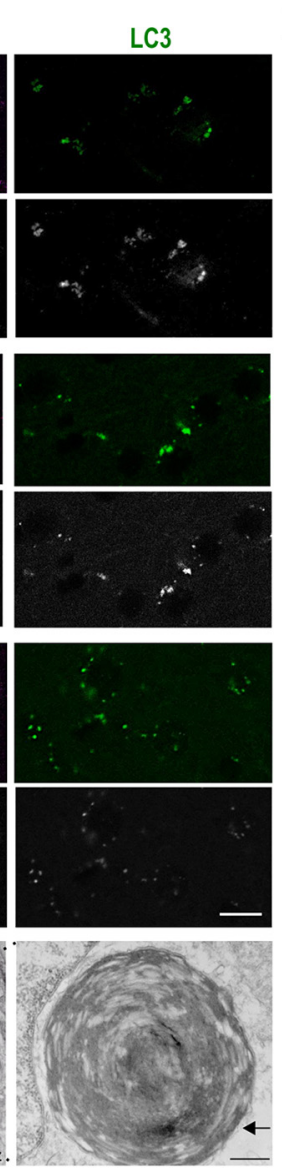

b

LAMP+-pSER-aggregates

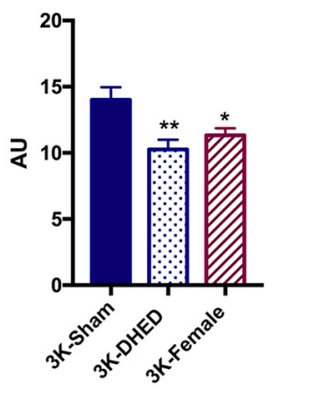

LC3+ counts / aggregates
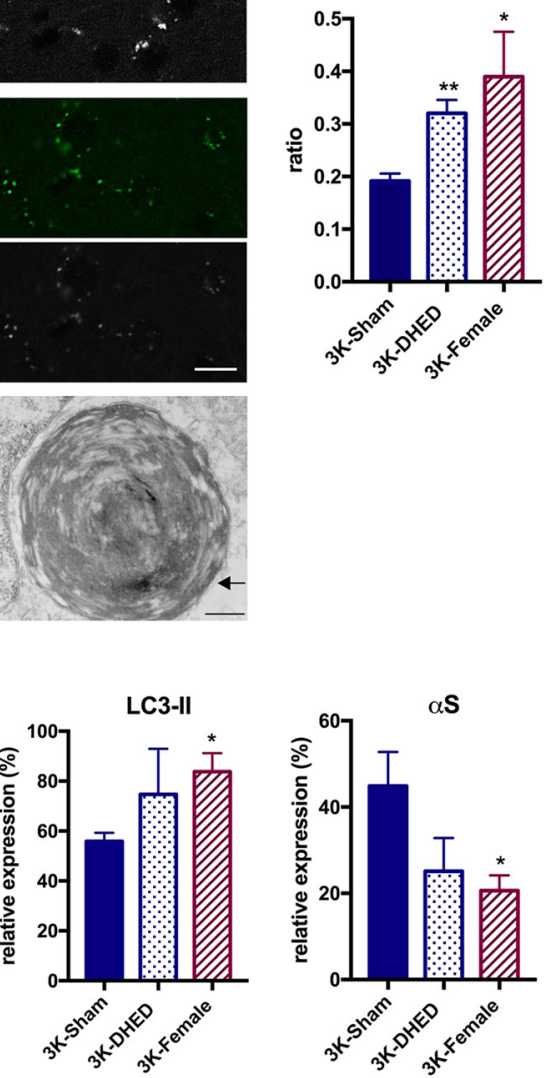

$\alpha \mathbf{S}$

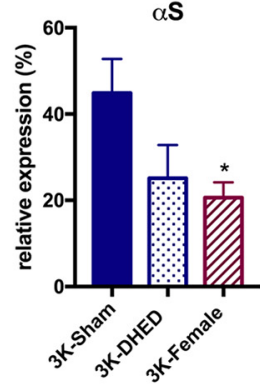

Figure 6. Recruitment of $\mathrm{LC}^{+}$vesicles to enlarged pSER129-lysosomal aggregates. $\boldsymbol{a}$, Confocal microscopy (merged and single-spectra images) of brain sections quadruple-labeled for pSer129 (red), LAMP-1 (magenta), LC3-II (green), and nuclei (DAPI, blue). Bottom, 8-bit (gray) images of the staining highlight the increase of of LC3 ${ }^{+}$puncta within the large pSer129 aggregates. Bottom panels show $15 \mathrm{G} 7$ hu aS immunogold labeling (arrow) at round, abnormal lysosomal inclusions (black asterisks) in cortex of young (4 months old) homozygous $3 \mathrm{~K}$ mice. The smaller inclusions are close to a larger round electron-dense perinuclear inclusion (N, nucleus) (white asterisk). Arrow points to hu aS immunogold labeling. $\boldsymbol{b}$, Colocalized points of the respective dual-color confocal images were analyzed using ImageJ colocalization highlighter and then estimated for their size by the ImageJ particle analyzer plugin. Quantification for colocalized aggregate sizes (pSER129LAMP1) and LC3 ${ }^{+}$counts in $n=10$ fields each of sections from each genotype.c, Quantitative WBs of autophagy-lysosomal marker quantified in d, show reduced LAMP1 accumulation, increase in LC3-II, and lesser membrane-associated $\alpha$ S in 3K female and by DHED treatment. Data are mean \pm SEM. One-way ANOVA post Tukey: ${ }^{*} p<0.05$; ${ }^{* *} p<0.01$. Scale bars: $\boldsymbol{a}$, top, $20 \mu \mathrm{m}$; bottom, $500 \mathrm{~nm}$.

fects of estrogen on the aggregate-prone excess $\alpha$ S monomers, we analyzed the pSER-lysosomal aggregate sizes in DHED-treated $3 \mathrm{~K}$ male vs. female cortical brain sections (Fig. $6 a, b)$. The aggregates were not counted in expression-matched WT mice because of the relative small numbers present in these mice (Nuber et al., 2018) (see also Fig. 4c). We observed that both DHED treatment and female sex significantly reduced aggregate sizes in $3 \mathrm{~K}$ cortex $(F=6.5, p=0.008$, one-way ANOVA). The decrease in PSER and LAMP-1 colocalization in DHEDtreated $3 \mathrm{~K}$ neurons $(p=0.003)$ is similar to the significant changes detected in female $3 \mathrm{~K}$ ( $3 \mathrm{~K}$ male vs $3 \mathrm{~K}$ female $p=0.02$ ) and suggests increase in autophagy turnover of pathological aggregates. To investigate this hypothesis, we analyzed LC3-II puncta overlapping with the pSER-LAMP-1 inclusions as a measure for autophagy regulation. One-way ANOVA confirmed significant changes $(F=3.9 ; p=0.04)$, and post hoc multiple comparisons showed the $\mathrm{LC}^{+}$and LAMP-1 overlapping puncta to significantly increase upon DHED treatment in $3 \mathrm{~K}$ males $(p=0.0015)$, similar to the significant change in level in female $3 \mathrm{~K}$ mice (Sham-3K male vs $3 \mathrm{~K}$ female: $p=0.04$ ).

We previously found homozygous $3 \mathrm{~K} \alpha \mathrm{S}$ expression to promote the $\mathrm{PD}$-like phenotype and underlying aggregate pa- 

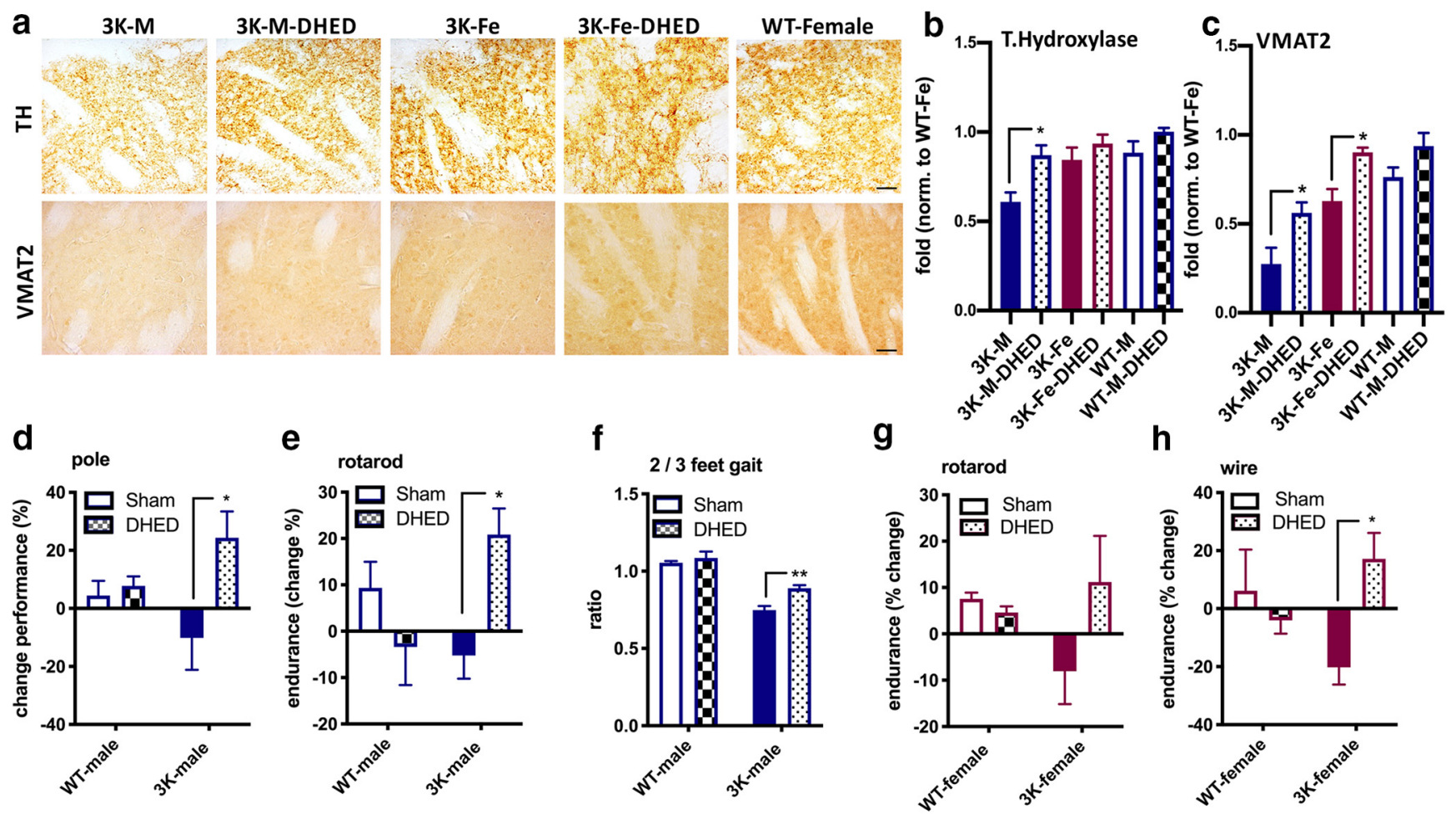

Figure 7. Elevating brain estrogen increases DAergic fiber densities and benefits motor behavior in $3 \mathrm{~K}$ mice. $\boldsymbol{a}$, Representative images of TH ${ }^{+}$nerve terminals and VMAT2 in $3 \mathrm{~K}$-Sham, $3 \mathrm{~K}$-DHED males and $3 \mathrm{~K}$ females and WT females ( $n=4$ each group). $\boldsymbol{b}, \boldsymbol{c}$, Relative TH and VMAT2 optical density was analyzed in the dorsal CPu. $\boldsymbol{d}$, Pharmacological rescue of motor deficits of male $3 \mathrm{~K}$ mice by DHED: increase in pole climbing performance after $90 \mathrm{~d}$ and $(\boldsymbol{e})$ fine motor skill on the accelerating rotarod and $(\boldsymbol{f})$ increased the 2- to 3 -feet body support on a treadmill. $\boldsymbol{g}$, Rotarod, and $(\boldsymbol{h})$ DHED benefit in wire performance in female $3 \mathrm{~K}$ mice. Data are mean \pm SEM. Two-way ANOVA post Tukey: ${ }^{*} p<0.05 ;{ }^{* *} p<0.01$. Scale bar, $50 \mu \mathrm{m}$.

thology in mice. Thus, we analyzed the ultrastructure inclusions in 4-month-old homozygous $3 \mathrm{~K}$ males. EM validated the LM-observed lysosomal pathology, showing highly abnormal endolysosomes and lysosomes that had a spectrum of abnormal appearances. This includes enlarged organelles with internal membranes tightly packed into circular stacks, located perinuclear in neuronal somata of cortex and substantia nigra (Fig. 6a, bottom).

In light of the reduced lysosomal foci by IHC, we asked whether overall protein level would validate the finding in Triton X-100cortical brain extracts (Fig. $6 c, d$ ). While LAMP1 and membranebound $\alpha \mathrm{S}$ level was decreased in DHED-treated 3K male brain extracts ( $p<0.01$ ), LC3-II protein level increased by DHED toward significantly changed level detected in female $3 \mathrm{~K}$ mice $(p=0.02)$, further substantiating autophagy turnover of the vesicle-rich $\alpha \mathrm{S}$ aggregates.

\section{DHED treatment improves dopaminergic fiber densities and associated motor deficits}

Since female sex preserved $\mathrm{TH}^{+}$fibers in $3 \mathrm{~K}$ mice (Fig. $3 b$ ), we quantified $\mathrm{TH}^{+}$densities of serial sections in the dorsal $\mathrm{CPu}$ of vehicle and DHED-treated 3K males (Fig. 7a, top). Two-way ANOVA indicated significant main effects of transgene $\left(F_{(2,35)}=\right.$ 6.698, $p=0.0034)$ and treatment $\left(F_{(1,35)}=10.51, p=0.002\right)$. Post hoc multiple comparisons showed significantly increased $\mathrm{TH}^{+}$densities in DHED-treated 10-month-old male 3K mice $(p=0.02)$ (Fig. $7 b)$. To further analyze DAergic nerve terminal integrity, we stained sections against the VMAT2, a synaptic vesicle marker reduced in PD (Miller et al., 1999). We found that the density of VMAT2 was increased upon DHED treatment in males and became similar to the level detected in $3 \mathrm{~K}$ females (Fig. $7 a$, bottom). Two-way ANOVA revealed a significant main effect of transgene $\left(F_{(2,35)}=23.28, p<0.0001\right)$ and treatment $\left(F_{(1,35)}=\right.$ $19.15, p=0.0001)$. Post hoc multiple comparisons showed DHED treatment to increase VMAT2-immunoreactive puncta in male $3 \mathrm{~K}(p=0.03)$ and female $3 \mathrm{~K}$ mice $(p=0.05)$, suggesting that DHED increased striatal fiber complexities in $3 \mathrm{~K}$ mice. No significant changes were detected between groups of phenotypically normal WT mice.

Finally, we investigated whether DHED-dependent increase in brain estradiol affected the motor performance by measuring untreated $3 \mathrm{~K}$ mice at baseline ( 7 months) vs. $90 \mathrm{~d}$ of treatment.

Within $90 \mathrm{~d}$ of treatment, $3 \mathrm{~K}$ males improved their time to climb down the pole $(24 \pm 9 \%)$ (Fig. $7 d$ ). Two-way ANOVA confirmed a significant interaction between treatment and genotype $\left(F_{(1,13)}=4.4, p=0.05\right)$. Post hoc multiple comparison showed a significant effect upon DHED treatment in $3 \mathrm{~K}$ males $(p=0.04)$. To further validate improvement in motor performance by DHED treatment, we analyzed balancing skills on the accelerating rotarod (Fig. 7 e). Within $90 \mathrm{~d}$ of treatment, $3 \mathrm{~K}$ males significantly improved their endurance on the rod $(\sim 23 \pm 9 \%)$. Two-way ANOVA confirmed a significant interaction between treatment and genotype $\left(F_{(1,13)}=7.9, p=0.02\right)$. Post hoc pairwise comparison revealed DHED treatment of $3 \mathrm{~K}$ males to improve endurance on the rotarod $(p=0.02)$. We previously showed that the fine motor impairment is based on irregular gait pattern $(\mathrm{Nu}-$ ber et al., 2018). Thus, we next photographically analyzed the fine paw patterns of mice running on a motorized belt. DHEDtreated 3K mice displayed an increase in secure gait (Fig. 7f). Two-way ANOVA indicated a significant main effect of treatment $\left(F_{(1,13)}=4.4, p=0.04\right)$ and genotype $\left(F_{(1,13)}=4.3, p=\right.$ $0.05)$, and post hoc multiple comparisons revealed an improved ratio of the 2 - to 3 -feet support $(p=0.03)$. In all cases, DHED treatment of WT $\alpha S$ male mice did not show significance in be- 
tween group differences, excluding direct effects of estradiol on the hu $\alpha \mathrm{S}$ protein. We further evaluated DHED treatment in female $3 \mathrm{~K}$ vs. female WT control mice (Fig. $7 g, h$ ). We did not find a significant improvement between $3 \mathrm{~K}$ females at baseline and after DHED treatment (data not shown). However, upon DHED treatment, $3 \mathrm{~K}$ female motor performance was mildly ameliorated, both in the rotarod $(11 \pm 9 \%)$ or wire $(17 \pm 9 \%)$, vs. a decline detected in vehicle-treated (Sham) $3 \mathrm{~K}$ female mice in either the rotarod $(-8 \pm 7 \%)$ or wire test $(-20 \pm 5 \%)$. Two-way ANOVA of the rotarod showed a nonsignificant interaction; however, multiple comparisons revealed a trend of DHED treatment to improve endurance $(p=0.2)$. Additionally, DHED treatment showed a significant interaction in the wire performance $\left(F_{(1,15)}=6.745, p=0.02\right)$ and post hoc multiple comparisons revealed improvement in $3 \mathrm{~K}$ females by DHED $(p=0.03)$ and thus further validating the effect to underlie $3 \mathrm{~K}$ neuropathology rather than direct hormone effects on motor behavior.

\section{Discussion}

Here, we investigated the relationship between the female sex steroid hormone estrogen and the development of the PD-like neuropathology in the $3 \mathrm{~K}$ mouse model of PD. We observed the PD-like pathologies being mitigated by the female sex, including a reduced shift of $\alpha \mathrm{S}$ tetramers toward membrane-bound and insoluble monomers, cortical and DAergic fiber loss, preserved DA level, and an overall improved behavior outcome. Specifically, the increase in the $\alpha \mathrm{S}$ T:M ratio and solubility were associated with an increase in autophagy turnover of excess aggregate-prone monomers, increased fiber complexities, and improvement of the motor phenotypes. Notably, we found that selective increase of estrogen (by DHED) in symptomatic $3 \mathrm{~K}$ brains alleviated these pathologies, suggesting action of this sex hormone in regulating the neuronal PD pathology. Consistent with a protective role of estrogen, we found that DHED treatment decreased the $\alpha \mathrm{S}$ monomer accumulation at membranes and the worsening of $\alpha \mathrm{S}$ aggregation, restored vesicle and neurite fiber complexity, and improved the motor phenotypes. These data, which present the first report on brain-estrogen treatment on $\alpha \mathrm{S}$ homeostasis in a transgenic PD mouse model, implicate interaction of estrogen with healthy $\alpha$ S tetramerization in regulating the subsequent PD-like neuropathology.

Our results support the hypothesis that estrogen protects against the severity of PD-like symptoms. Similar to our findings, other studies have reported estradiol to stimulate neuroprotective mechanisms being lost by KO of parkin (Rodríguez-Navarro et al., 2008). Furthermore, estrogen treatment has been associated with increased $\mathrm{TH}^{+}$fiber sprouting and/or survival in 6-OHDA (Gillies and McArthur, 2010a,b) and in an MPTP (Liu and Dluzen, 2007) toxin-based model. In parallel, we observe an increase in $\mathrm{TH}^{+}$fibers by female sex and by elevation of brainestradiol in DHED-treated males.

In previous studies using transgenic animal models of $\mathrm{PD}$, sex differences in $\alpha \mathrm{S}$ aggregation-pathology are not observed and/or reported (Gillies et al., 2014).

It is unclear why estrogen status is associated with $\alpha \mathrm{S}$ level and the induced pathology in the present model but has not yet been observed or described in others. One potential important difference is methods used to capture all $\alpha \mathrm{S}$ forms and for detection (i.e., to capture the different pools of $\alpha \mathrm{S}$ ranging from soluble tetramers to membrane-bound and/or insoluble $\alpha \mathrm{S}$ monomers to $\mathrm{pSER}^{+}$deposited forms). In this study, we found that female sex increases $\alpha \mathrm{S}$ T:M ratio, as determined by intact-cell crosslink- ing, which not only measures soluble $\alpha \mathrm{S}$ forms but also reflects aggregate-resistant $\alpha \mathrm{S}$ forms (Bartels et al., 2011).

Because the $\alpha \mathrm{S}$ T:M ratio is increasingly recognized as a relevant measure of $\alpha$ S pathology (Wooddell et al., 2017; Kim et al., 2018; Nuber et al., 2018; Fanning et al., 2019), we analyzed the potential hormone regulation on this $\alpha \mathrm{S}$ homeostasis. Although we observed a statistically nonsignificant trend toward the $\alpha \mathrm{S} 60$ tetramer level, female estrogen significantly increased $3 \mathrm{~K} \alpha \mathrm{S}$ tetramerization toward the physiological T:M ratio of phenotypically normal WT mice while displaying lesser $\alpha \mathrm{S} 14$ monomer signals at the Triton X-100-soluble membrane fraction. This was consistently observed by DHED treatment in 10-month-old $3 \mathrm{~K}$ male mice with an effect in reducing the signals of excess monomers. Thus, estrogen likely regulates the aggregate-prone monomeric $\alpha \mathrm{S}$ pool. Accordingly, the aggregate sizes were decreased by female sex and DHED treatment vs. age-matched $3 \mathrm{~K}$ males. At this point, it is unclear how continuous estrogen can increase the vesicle fusion processes relevant for autophagy degradation, although our RNA expression data predict ER $\alpha$-dependent signaling impairment in $3 \mathrm{~K}$ mice (Fig. 4). Additionally, we observe a somewhat finer distribution of the ER $\alpha$ signals by DHED treatment. Interestingly, previous studies showed subcellular ER $\alpha$ to localize on synaptic vesicle membranes (Adams et al., 2002), and this may relate to improved dendritic branching (Audesirk et al., 2003), which suggests a potential important connection between the effect of estrogen on DAergic and/or cortical fiber networks in our $3 \mathrm{~K}$ mice. Therefore, 3K monomer-associated vesicle aggregates may render estrogen-regulated protective $\mathrm{ER} \alpha$ signaling inert. Particularly, the increase in striatal VMAT2 staining by DHED treatment in male and female $3 \mathrm{~K}$ mice may further reflect on the observed increase in vesicle abundance not only at the somatic but also the synaptic level, and hence may be a sensitive marker for the beneficial estradiol effects on vesicle flux in neurons.

In addition to the previously described consequence in aggregation and behavior phenotypes, the results of this study also provide interesting insight into the relationship of soluble $\alpha \mathrm{S}$ tetramerization and neurite fiber densities. In $3 \mathrm{~K}$ females, we found a strong positive association of increased $\alpha \mathrm{S}$ solubility and vesicle abundance, and a lesser degree of fiber loss. Therefore, decreasing $\alpha \mathrm{S}$ monomer level at membranes may further reduce formation of vesicle-rich $\alpha \mathrm{S}$ aggregates and allow vesicle and nerve fiber compensatory effects to the $\alpha \mathrm{S}$ induced toxicity. Further, we observed a correlation between female sex estrogen in $\alpha \mathrm{S}$ tetramerization and improved motor phenotypes, providing additional evidence of a causative effect of shifting $\alpha \mathrm{S}$ tetramers toward excess monomers upstream the PD-like motor syndrome. Together, the results suggest that the PD-like motor syndrome in $3 \mathrm{~K}$ mice is impacted by upstream $\alpha \mathrm{S}$ tretramerization, autophagy vesicle fusion, and fiber integrity.

In conclusion, the results of this study provide novel insights into the roles of the female sex steroid estrogen in the regulation of $\alpha \mathrm{S}$-induced PD-like phenotypes. Our study in a robust PD mouse model supports the hypothesis that estrogen is of benefit for altered $\alpha \mathrm{S}$ T:M equilibrium that can occur upstream of PDrelevant neuropathology and motor syndrome. We show that $17 \beta$-estradiol treatment can effectively reduce an abnormal shift of physiological tetramers to excess monomers and thereby ameliorate attendant neuropathology, even after its onset. Additional studies are needed not only to clarify the relationship between $\mathrm{ER} \alpha$ signaling and physiological $\alpha \mathrm{S}$ tetramerization but also to elucidate the observed mitigation of an elevated level of SCD-1, an enzyme whose activity we and others recently found to destabilize $\alpha$ S tetramers (Fanning et al., 2019) and increase $\alpha$ S toxicity 
(Vincent et al., 2018) in cultured neurons, and that SCD-1 inhibition can decrease the PD-like neuropathology in our mouse model of PD.

\section{References}

Adams MM, Fink SE, Shah RA, Janssen WG, Hayashi S, Milner TA, McEwen BS, Morrison JH (2002) Estrogen and aging affect the subcellular distribution of estrogen receptor-alpha in the hippocampus of female rats. J Neurosci 22:3608-3614.

Alves G, Forsaa EB, Pedersen KF, Dreetz Gjerstad M, Larsen JP (2008) Epidemiology of Parkinson's disease. J Neurol 255 [Suppl 5]:18-32.

Audesirk T, Cabell L, Kern M, Audesirk G (2003) $\beta$-Estradiol influences differentiation of hippocampal neurons in vitro through an estrogen receptor-mediated process. Neuroscience 121:927-934.

Baldereschi M, Di Carlo A, Rocca WA, Vanni P, Maggi S, Perissinotto E, Grigoletto F, Amaducci L, Inzitari D (2000) Parkinson's disease and parkinsonism in a longitudinal study: two-fold higher incidence in men. ILSA working group. Italian Longitudinal Study on Aging. Neurology 55:1358-1363.

Bartels T, Choi JG, Selkoe DJ (2011) $\alpha$-Synuclein occurs physiologically as a helically folded tetramer that resists aggregation. Nature 477:107-110.

Blanchet PJ, Fang J, Hyland K, Arnold LA, Mouradian MM, Chase TN (1999) Short-term effects of high-dose 17beta-estradiol in postmenopausal PD patients: a crossover study. Neurology 53:91-95.

Bourque M, Morissette M, Di Paolo T (2019) Repurposing sex steroids and related drugs as potential treatment for Parkinson's disease. Neuropharmacology 147:37-54.

Chen S, Asakawa T, Ding S, Liao L, Zhang L, Shen J, Yu J, Sugiyama K, Namba H, Li C (2013) Chaihu-Shugan-San administration ameliorates perimenopausal anxiety and depression in rats. PLoS One 8:e72428.

Dettmer U, Newman AJ, Luth ES, Bartels T, Selkoe D (2013) In vivo crosslinking reveals principally oligomeric forms of alpha-synuclein and betasynuclein in neurons and non-neural cells. J Biol Chem 288:6371-6385.

Dettmer U, Newman AJ, Soldner F, Luth ES, Kim NC, von Saucken VE, Sanderson JB, Jaenisch R, Bartels T, Selkoe D (2015) Parkinson-causing alpha-synuclein missense mutations shift native tetramers to monomers as a mechanism for disease initiation. Nat Commun 6:7314.

Dye RV, Miller KJ, Singer EJ, Levine AJ (2012) Hormone replacement therapy and risk for neurodegenerative diseases. Int J Alzheimers Dis 2012: 258454 .

Fanning S, Haque A, Imberdis T, Baru V, Barrasa MI, Nuber S, Termine D, Ramalingam N, Ho GP, Noble T, Sandoe J, Lou Y, Landgraf D, Freyzon Y, Newby G, Soldner F, Terry-Kantor E, Kim TE, Hofbauer HF, Becuwe M, et al. (2019) Lipidomic analysis of alpha-synuclein neurotoxicity identifies stearoyl CoA desaturase as a target for Parkinson treatment. Mol Cell 73:1001-1014.e8.

Forno LS (1996) Neuropathology of Parkinson's disease. J Neuropathol Exp Neurol 55:259-272.

Franklin KB, Paxinos G (2008) The mouse brain in stereotaxic coordinates, Ed 3. San Diego: Academic.

Gammie SC, Edelmann MN, Mandel-Brehm C, D’Anna KL, Auger AP, Stevenson SA (2008) Altered dopamine signaling in naturally occurring maternal neglect. PLoS One 3:e1974.

Gélinas S, Bureau G, Valastro B, Massicotte G, Cicchetti F, Chiasson K, Gagne B, Blanchet J, Martinoli MG (2004) Alpha and beta estradiol protect neuronal but not native PC12 cells from paraquat-induced oxidative stress. Neurotox Res 6:141-148.

Gillies GE, McArthur S (2010a) Independent influences of sex steroids of systemic and central origin in a rat model of Parkinson's disease: a contribution to sex-specific neuroprotection by estrogens. Horm Behav 57: 23-34.

Gillies GE, McArthur S (2010b) Estrogen actions in the brain and the basis for differential action in men and women: a case for sex-specific medicines. Pharmacol Rev 62:155-198.

Gillies GE, Pienaar IS, Vohra S, Qamhawi Z (2014) Sex differences in Parkinson's disease. Front Neuroendocrinol 35:370-384.

Goedert M (2001) Alpha-synuclein and neurodegenerative diseases. Nat Rev Neurosci 2:492-501.

Hayashida K, Oyanagi S, Mizutani Y, Yokochi M (1993) An early cytoplasmic change before Lewy body maturation: an ultrastructural study of the substantia nigra from an autopsy case of juvenile parkinsonism. Acta Neuropathol 85:445-448.
Ivanova T, Beyer C (2003) Estrogen regulates tyrosine hydroxylase expression in the neonate mouse midbrain. J Neurobiol 54:638-647.

Kett LR, Dauer WT (2016) Endolysosomal dysfunction in Parkinson's disease: Recent developments and future challenges. Mov Disord 31:1433-1443.

Kim S, Yun SP, Lee S, Umanah GE, Bandaru VV, Yin X, Rhee P, Karuppagounder SS, Kwon SH, Lee H, Mao X, Kim D, Pandey A, Lee G, Dawson VL, Dawson TM, Ko HS (2018) GBAl deficiency negatively affects physiological alpha-synuclein tetramers and related multimers. Proc Natl Acad Sci U S A 115:798-803.

Kishi Y, Takahashi J, Koyanagi M, Morizane A, Okamoto Y, Horiguchi S, Tashiro K, Honjo T, Fujii S, Hashimoto N (2005) Estrogen promotes differentiation and survival of dopaminergic neurons derived from human neural stem cells. J Neurosci Res 79:279-286.

Kosaka K (1978) Lewy bodies in cerebral cortex: report of three cases. Acta Neuropathol(Berl) 42:127-134.

Kurtzke JF, Goldberg ID (1988) Parkinsonism death rates by race, sex, and geography. Neurology 38:1558-1561.

Kuusisto E, Parkkinen L, Alafuzoff I (2003) Morphogenesis of Lewy bodies: dissimilar incorporation of alpha-synuclein, ubiquitin, and p62. J Neuropathol Exp Neurol 62:1241-1253.

Lee BR, Kamitani T (2011) Improved immunodetection of endogenous alpha-synuclein. PLoS One 6:e23939.

Liu B, Dluzen DE (2007) Oestrogen and nigrostriatal dopaminergic neurodegeneration: animal models and clinical reports of Parkinson's disease. Clin Exp Pharmacol Physiol 34:555-565.

Liu X, Shi H (2015) Regulation of estrogen receptor alpha expression in the hypothalamus by sex steroids: implication in the regulation of energy homeostasis. Int J Endocrinol 2015:949085.

Lu Y, Sareddy GR, Wang J, Wang R, Li Y, Dong Y, Zhang Q, Liu J, O'Connor JC, Xu J, Vadlamudi RK, Brann DW (2019) Neuron-derived estrogen regulates synaptic plasticity and memory. J Neurosci 39:2792-2809.

Lundin JI, Ton TG, LaCroix AZ, Longstreth WT, Franklin GM, Swanson PD, Smith-Weller T, Racette BA, Checkoway H (2014) Formulations of hormone therapy and risk of Parkinson's disease. Mov Disord 29:1631-1636.

Miller GW, Erickson JD, Perez JT, Penland SN, Mash DC, Rye DB, Levey AI (1999) Immunochemical analysis of vesicular monoamine transporter (VMAT2) protein in Parkinson's disease. Exp Neurol 156:138-148.

Newman AJ, Selkoe D, Dettmer U (2013) A new method for quantitative immunoblotting of endogenous alpha-synuclein. PLoS One 8:e81314.

Nuber S, Petrasch-Parwez E, Winner B, Winkler J, von Hörsten S, Schmidt T, Boy J, Kuhn M, Nguyen HP, Teismann P, Schulz JB, Neumann M, Pichler BJ, Reischl G, Holzmann C, Schmitt I, Bornemann A, Kuhn W, Zimmermann F, Servadio A, et al. (2008) Neurodegeneration and motor dysfunction in a conditional model of Parkinson's disease. J Neurosci 28 : 2471-2484.

Nuber S, Harmuth F, Kohl Z, Adame A, Trejo M, Schönig K, Zimmermann F, Bauer C, Casadei N, Giel C, Calaminus C, Pichler BJ, Jensen PH, Müller CP, Amato D, Kornhuber J, Teismann P, Yamakado H, Takahashi R, Winkler J, et al. (2013) A progressive dopaminergic phenotype associated with neurotoxic conversion of alpha-synuclein in BAC-transgenic rats. Brain 136:412-432.

Nuber S, Rajsombath M, Minakaki G, Winkler J, Müller CP, Ericsson M, Caldarone B, Dettmer U, Selkoe DJ (2018) Abrogating native alphasynuclein tetramers in mice causes a L-DOPA-responsive motor syndrome closely resembling Parkinson's disease. Neuron 100:75-90.e5

Paquette A, Wang D, Jankowski M, Gutkowska J, Lavoie JM (2008) Effects of ovariectomy on PPAR alpha, SREBP-1c, and SCD-1 gene expression in the rat liver. Menopause 15:1169-1175.

Paxinos G, Franklin KB (2001) The mouse brain in stereotaxic coordinates, Ed 2. San Diego: Academic.

Prokai L, Nguyen V, Szarka S, Garg P, Sabnis G, Bimonte-Nelson HA, McLaughlin KJ, Talboom JS, Conrad CD, Shughrue PJ, Gould TD, Brodie A, Merchenthaler I, Koulen P, Prokai-Tatrai K (2015) The prodrug DHED selectively delivers 17beta-estradiol to the brain for treating estrogen-responsive disorders. Sci Transl Med 7:297ra113.

Ragonese P, D’Amelio M, Salemi G, Aridon P, Gammino M, Epifanio A, Morgante L, Savettieri G (2004) Risk of Parkinson disease in women: effect of reproductive characteristics. Neurology 62:2010-2014.

Ragonese P, D'Amelio M, Callari G, Salemi G, Morgante L, Savettieri G (2006) Age at menopause predicts age at onset of Parkinson's disease. Mov Disord 21:2211-2214. 
Reisert I, Han V, Lieth E, Toran-Allerand D, Pilgrim C, Lauder J (1987) Sex steroids promote neurite growth in mesencephalic tyrosine hydroxylase immunoreactive neurons in vitro. Int J Dev Neurosci 5:91-98.

Rocca WA, Grossardt BR, Maraganore DM (2008) The long-term effects of oophorectomy on cognitive and motor aging are age dependent. Neurodegener Dis 5:257-260.

Rodríguez-Navarro JA, Solano RM, Casarejos MJ, Gomez A, Perucho J, de Yébenes JG, Mena MA (2008) Gender differences and estrogen effects in parkin null mice. J Neurochem 106:2143-2157.

Rossouw JE, Anderson GL, Prentice RL, LaCroix AZ, Kooperberg C, Stefanick ML, Jackson RD, Beresford SA, Howard BV, Johnson KC, Kotchen JM, Ockene J (2002) Risks and benefits of estrogen plus progestin in healthy postmenopausal women: principal results from the Women's health initiative randomized controlled trial. JAMA 288:321-333.

Schlachetzki JC, Marxreiter F, Regensburger M, Kulinich A, Winner B, Winkler J (2014) Increased tyrosine hydroxylase expression accompanied by glial changes within the non-lesioned hemisphere in the 6-hydroxydopamine model of Parkinson's disease. Restor Neurol Neurosci 32:447-462.

Solis O, Limón DI, Flores-Hernández J, Flores G (2007) Alterations in dendritic morphology of the prefrontal cortical and striatum neurons in the unilateral 6-OHDA-rat model of Parkinson's disease. Synapse 61:450-458.

Stuart EB, Thompson JM, Rhees RW, Lephart ED (2001) Steroid hormone influence on brain calbindin- $\mathrm{D}(28 \mathrm{~K})$ in male prepubertal and ovariectomized rats. Brain Res Dev Brain Res 129:125-133.

Tsang KL, Ho SL, Lo SK (2000) Estrogen improves motor disability in parkinsonian postmenopausal women with motor fluctuations. Neurology 54:2292-2298.
Tschiffely AE, Schuh RA, Prokai-Tatrai K, Prokai L, Ottinger MA (2016) A comparative evaluation of treatments with 17beta-estradiol and its brainselective prodrug in a double-transgenic mouse model of Alzheimer's disease. Horm Behav 83:39-44.

Tschiffely AE, Schuh RA, Prokai-Tatrai K, Ottinger MA, Prokai L (2018) An exploratory investigation of brain-selective estrogen treatment in males using a mouse model of Alzheimer's disease. Horm Behav 98:16-21.

Vincent BM, Tardiff DF, Piotrowski JS, Aron R, Lucas MC, Chung CY, Bacherman H, Chen Y, Pires M, Subramaniam R, Doshi DB, Sadlish H, Raja WK, Solís EJ, Khurana V, Le Bourdonnec B, Scannevin RH, Rhodes KJ (2018) Inhibiting stearoyl-CoA desaturase ameliorates alpha-synuclein cytotoxicity. Cell Rep 25:2742-2754.31.

Watanabe I, Vachal E, Tomita T (1977) Dense core vesicles around the Lewy body in incidental Parkinson's disease: an electron microscopic study. Acta Neuropathol 39:173-175.

Wooddell LJ, Kaburu SSK, Murphy AM, Suomi SJ, Dettmer AM (2017) Rank acquisition in rhesus macaque yearlings following permanent maternal separation: the importance of the social and physical environment. Dev Psychobiol 59:863-875.

Xu L, Bhattacharya S, Thompson D (2018) Re-designing the alphasynuclein tetramer. Chem Commun (Camb) 54:8080-8083.

Zhang QG, Wang R, Tang H, Dong Y, Chan A, Sareddy GR, Vadlamudi RK, Brann DW (2014) Brain-derived estrogen exerts anti-inflammatory and neuroprotective actions in the rat hippocampus. Mol Cell Endocrinol 389:84-91. 